\title{
Article \\ Surface Coverage- and Excitation Laser Wavelength-Dependent Luminescence Properties of U(VI) Species Adsorbed on Amorphous $\mathrm{SiO}_{2}$
}

\author{
Euo Chang Jung ${ }^{1, * \mathbb{D}}$, Yongheum Jo ${ }^{2,+}$, Tae-Hyeong Kim ${ }^{1}$, Hee-Kyung Kim ${ }^{1} \mathbb{D}$, Hye-Ryun Cho ${ }^{1}$, Wansik Cha ${ }^{1} \mathbb{D}$, \\ Min Hoon Baik ${ }^{3}$ iD and Jong-Il Yun ${ }^{2}$ (D)
}

check for

updates

Citation: Jung, E.C.; Jo, Y.; Kim, T.-H.; Kim, H.-K.; Cho, H.-R.; Cha, W.; Baik, M.H.; Yun, J.-I. Surface Coverageand Excitation Laser WavelengthDependent Luminescence Properties of U(VI) Species Adsorbed on Amorphous $\mathrm{SiO}_{2}$. Minerals 2022, 12, 230. https://doi.org/10.3390/ $\min 12020230$

Academic Editors: Katharina Müller and Norbert Jordan

Received: 16 November 2021

Accepted: 8 February 2022

Published: 10 February 2022

Publisher's Note: MDPI stays neutral with regard to jurisdictional claims in published maps and institutional affiliations.

Copyright: (C) 2022 by the authors. Licensee MDPI, Basel, Switzerland. This article is an open access article distributed under the terms and conditions of the Creative Commons Attribution (CC BY) license (https:/ / creativecommons.org/licenses/by/ $4.0 /)$.
1 Nuclear Chemistry Research Team, Korea Atomic Energy Research Institute, Daejeon 34057, Korea; thkim@kaeri.re.kr (T.-H.K.); hkim11@kaeri.re.kr (H.-K.K.); hrcho@kaeri.re.kr (H.-R.C.); wscha@kaeri.re.kr (W.C.)

2 Department of Nuclear and Quantum Engineering, KAIST, Daejeon 34141, Korea; yongheum.jo@kit.edu (Y.J.); jiyun@kaist.ac.kr (J.-I.Y.)

3 Disposal Safety Evaluation Research Division, Korea Atomic Energy Research Institute, Daejeon 34057, Korea; mhbaik@kaeri.re.kr

* Correspondence: ecjung@kaeri.re.kr

† Present Address: Institute for Nuclear Waste Disposal (INE), Karlsruhe Institute of Technology (KIT), 76344 Karlsruhe, Germany.

\begin{abstract}
Time-resolved luminescence spectroscopy is usefully used to identify U(VI) surface species adsorbed on $\mathrm{SiO}_{2}$. However, the cause of the inconsistent luminescence lifetimes and spectral shapes reported previously remains undetermined. In this study, the U(VI) surface coverage $(\Gamma)$ and excitation laser wavelength $\left(\lambda_{\mathrm{ex}}\right)$ were examined as the predominant factors governing the luminescence properties of $\mathrm{U}(\mathrm{VI})$ surface species. At neutral $\mathrm{pH}$, the luminescence lifetimes of $\mathrm{U}(\mathrm{VI})$ surface species increased with decreasing $\Gamma$. In the low- $\Gamma$ region, where a relatively large number of adjacent surface sites are involved in the formation of multidentate surface complexes, the displacement of more number of coordinated water molecules in the equatorial plane of U(VI) results in a longer lifetime. The $\mathrm{pH}$-dependent luminescence lifetimes of $\mathrm{U}(\mathrm{VI})$ surface species at the same $\mathrm{U}(\mathrm{VI})$ to $\mathrm{SiO}_{2}$ concentration ratio in the $\mathrm{pH}$ range of 4.5-7.5 also explain the effect of the surface binding sites on the luminescence lifetime. The time-resolved luminescence properties of the U(VI) surface species were also investigated at different excitation wavelengths. Continued irradiation of the $\mathrm{SiO}_{2}$ surface with a UV laser beam at $\lambda_{\mathrm{ex}}=266 \mathrm{~nm}$ considerably reduced the luminescence intensities of the U(VI) surface species. The higher the laser pulse energy, the greater the decrease in luminescence intensity. Laser-induced thermal desorption (LITD) of U(VI) surface species is suggested to be the origin of the decrease in luminescence intensity. LITD effects were not observed at $\lambda_{\mathrm{ex}}=355$ and $422 \mathrm{~nm}$, even at high laser pulse energies.
\end{abstract}

Keywords: adsorption; desorption; uranium; $\mathrm{SiO}_{2} ; \mathrm{U}(\mathrm{VI})$ surface species; time-resolved luminescence spectroscopy

\section{Introduction}

Environmentally mobile uranium exists in the hexavalent oxidation state (U(VI)) under oxic conditions. Silicon dioxide $\left(\mathrm{SiO}_{2}\right)$ is an abundant component of geological media and clay minerals. The adsorption of $\mathrm{U}(\mathrm{VI})$ onto $\mathrm{SiO}_{2}$ surfaces has been extensively studied to understand its transport behavior under geochemical conditions [1-4]. Recent reviews have described related studies of several mineral surfaces [5-7]. The adsorption characteristics of $\mathrm{U}(\mathrm{VI})$ onto $\mathrm{SiO}_{2}$ surfaces have been investigated at the molecular scale using spectroscopic techniques, such as extended X-ray absorption fine structure (EXAFS) spectroscopy [8-12], $X$-ray photoelectron spectroscopy $[13,14]$, and time-resolved laser-induced fluorescence spectroscopy (TRLFS) [13-24]. Among these techniques, TRLFS has received considerable 
attention because of its high sensitivity. Information about the number of distinct $\mathrm{U}(\mathrm{VI})$ surface species at very low concentrations can be obtained by measuring the luminescence properties: intensity, lifetime, peak position, and spectral shape.

In previous TRLFS studies of $\mathrm{U}(\mathrm{VI})$-adsorbed $\mathrm{SiO}_{2}$ suspensions, at least two $\mathrm{pH}$ dependent luminescent $\mathrm{U}(\mathrm{VI})$ species have been distinguished. These species are prominent under acidic and near-neutral $\mathrm{pH}$ conditions [13,17]. The surface complexation of $\mathrm{UO}_{2}{ }^{2+}$ results in the formation of $\equiv \mathrm{SiO}_{2} \mathrm{UO}_{2}$ under acidic $\mathrm{pH}$ conditions. The formation of this surface complex has been unquestionably confirmed by EXAFS studies, indicating the inner-sphere bidentate bonding structure, at approximately $\mathrm{pH} 4$ in the $\mathrm{U}(\mathrm{VI})$ concentration ([U(VI)]) range of $5 \times 10^{-2}-2 \times 10^{-5} \mathrm{M}[9,10]$. Under the near-neutral $\mathrm{pH}$ condition, a red-shift of approximately a few nanometres in the luminescence peak positions in comparison to those of $\equiv \mathrm{SiO}_{2} \mathrm{UO}_{2}$ represents the surface complexation of $\mathrm{U}(\mathrm{VI})$ hydroxo species. Two different complexes, $\equiv \mathrm{SiO}_{2}\left(\mathrm{UO}_{2}\right) \mathrm{OH}^{-}$and $\equiv \mathrm{SiO}_{2}\left(\mathrm{UO}_{2}\right)_{3}(\mathrm{OH})_{5}{ }^{-}$, have been proposed $[13,17]$. However, the spectroscopic differences between these U(VI)hydroxo surface complexes remain a subject of discussion. Following EXAFS studies, Sylwester et al. [11] reported the formation of polynuclear surface complexes including surface precipitates by observing the $\mathrm{U}-\mathrm{U}$ interatomic distance at approximately $\mathrm{pH} 6.5$ and $[\mathrm{U}(\mathrm{VI})]=4.15 \times 10^{-5} \mathrm{M}$, whereas Reich et al. $[9,10]$ reported a contradictory result. Among TRLFS researchers, Gabriel et al. proposed $\equiv \mathrm{SiO}_{2}\left(\mathrm{UO}_{2}\right) \mathrm{OH}^{-}$as the $\mathrm{U}(\mathrm{VI})$-hydroxo surface complex in the low $[\mathrm{U}(\mathrm{VI})]$ range of $0.1-1 \mu \mathrm{M}$ onto $\mathrm{SiO}_{2}$ above $\mathrm{pH} 6.7$ [17]. In contrast, Kowal-Fouchard et al. reported that the $\mathrm{U}(\mathrm{VI})$ surface species were dominated by the $\mathrm{U}(\mathrm{VI})$ aqueous species; thus, $\equiv \mathrm{SiO}_{2}\left(\mathrm{UO}_{2}\right)_{3}(\mathrm{OH})_{5}{ }^{-}$was suggested to be the $\mathrm{U}(\mathrm{VI})$-hydroxo surface complex at high [U(VI)] of $0.1 \mathrm{mM}$ above $\mathrm{pH} 5.9$ [13]. Similar luminescence lifetimes of $360 \pm 50 \mu$ s and $400 \pm 30 \mu$ s were observed for $\equiv \mathrm{SiO}_{2}\left(\mathrm{UO}_{2}\right) \mathrm{OH}^{-}$and $\equiv \mathrm{SiO}_{2}\left(\mathrm{UO}_{2}\right)_{3}(\mathrm{OH})_{5}{ }^{-}$, respectively, in these works $[13,17]$. However, the luminescence spectral shapes of these $\mathrm{U}(\mathrm{VI})$-hydroxo surface species have not yet been compared in detail. It is also of interest to note that the luminescence spectral shapes observed in other studies differ markedly for $\mathrm{U}(\mathrm{VI})$ surface species under near-neutral $\mathrm{pH}$ conditions $[18,23,24]$. Moreover, a wide range of luminescence lifetimes has been reported. For instance, lifetimes of 192-258 $\mu$ s [23], $308 \mu \mathrm{s}$ [18], $361.8 \pm 206.4 \mu \mathrm{s}$ [20], longer than $450 \mu \mathrm{s}$ [21], and $599 \pm 60 \mu \mathrm{s}$ [24] have been reported for $\mathrm{U}(\mathrm{VI})$ surface species at $\mathrm{pH} 7-8$. Until now, the reasons for these inconsistent lifetimes have not been clarified. The main results of previously reported $\mathrm{U}(\mathrm{VI})$ surface species, thermodynamic surface complexation constants, and luminescence characteristics are summarized in Table S1 of the Supplementary Materials.

The ambiguous luminescence properties are presumably due to the application of various experimental factors related to both the sample preparation and TRLFS instrumentation. Solution and surface parameters, such as $\mathrm{pH}$ and $\mathrm{U}(\mathrm{VI})$ surface coverage $(\Gamma)$, are representative factors for sample preparation. $\Gamma$ is determined by the specific surface area (SSA), adsorbed [U(VI)], and mass-to-volume ratio $(m / v)$ of $\mathrm{SiO}_{2}$ and plays a significant role in the formation of surface complexes. It is known that polynuclear surface complexes are formed under high $\Gamma$ conditions for montmorillonite, quartz, and Al hydroxide [25-27]. On the other hand, the excitation laser wavelength $\left(\lambda_{\text {ex }}\right)$ and laser pulse energy can be chosen as experimental factors for TRLFS instrumentation. In most TRLFS measurements, luminescence spectra have been obtained at $\lambda_{\mathrm{ex}}=266,355 \mathrm{~nm}$ and $415-430 \mathrm{~nm}$. Despite the fact that the first electronic absorption band of $\mathrm{U}(\mathrm{VI})$ is in the wavelength range of $415-430 \mathrm{~nm}[28,29], 266 \mathrm{~nm}$ UV laser beams are widely adopted owing to their high luminescence quantum yields [30,31]. The luminescence intensities measured by using different excitation wavelengths have been compared for aqueous $\mathrm{U}(\mathrm{VI})$ complexes and solid-state $\mathrm{U}(\mathrm{VI})$ compounds [32,33], but relatively little attention has been paid to the $\lambda_{\text {ex }}$-dependent luminescence properties of the $\mathrm{U}(\mathrm{VI})$ surface species. The $\lambda_{\text {ex }}$-dependent luminescence intensity change during laser irradiation has only been demonstrated for the $\mathrm{U}(\mathrm{VI})$ adsorbed titanium dioxide $\left(\mathrm{TiO}_{2}\right)$ surface $[34,35]$. The decreases in the luminescence intensities of $\mathrm{U}(\mathrm{VI})$ surface species on $\mathrm{TiO}_{2}$ have been explained by the photoreduction of $\mathrm{U}(\mathrm{VI})$ to the tetravalent oxidation state (U(IV)) [34,35]. As the band gap energy of $\mathrm{TiO}_{2}$ is 
slightly above $3.0 \mathrm{eV}$, irradiation of laser light shorter than approximately $\lambda_{\mathrm{ex}}=413 \mathrm{~nm}$ provides photoelectrons from $\mathrm{TiO}_{2}$ to $\mathrm{U}(\mathrm{VI})$ [36]. In contrast, photoelectron generation is difficult at the $\mathrm{SiO}_{2}$-water interface because amorphous $\mathrm{SiO}_{2}$ has a bandgap energy of approximately $9.0 \mathrm{eV}$, approximately three times greater than that of $\mathrm{TiO}_{2}$ [37]. Accordingly, the $\lambda_{\text {ex }}$-dependent luminescence intensity change of $\mathrm{U}(\mathrm{VI})$ surface species on $\mathrm{SiO}_{2}$ observed in this study has rarely been considered so far.

The objective of the present study was to elucidate the origin of the ambiguous luminescence properties measured using TRLFS. First, the $\Gamma$-dependent luminescence properties of $\mathrm{U}(\mathrm{VI})$ surface species were examined at $\lambda_{\mathrm{ex}}=266 \mathrm{~nm}$ for the three different $\mathrm{SiO}_{2}$ samples (two high SSA samples and one low SSA sample) at pH 7.5. The luminescence spectra were analyzed according to the decomposition processes via both parallel factor (PARAFAC) analysis [38-40] and manual subtraction method [22,41,42] using Origin 9.5. The results obtained from the latter method, in particular, were discussed in detail to understand the origin of the ambiguous luminescence lifetimes. Comparisons of the luminescence spectra and lifetimes between samples at various $\Gamma$ provided new insights that resolve the confusion reported previously. The effects of the $\mathrm{U}(\mathrm{VI})-\mathrm{SiO}_{2}$ reaction time (called the 'ageing' effect) on the luminescence properties were also inspected. Second, the $\lambda_{\text {ex }}$-dependent luminescence properties were examined in the laser pulse energy range of $0.1-2.4 \mathrm{~mJ}$ at $\lambda_{\mathrm{ex}}=266,355$, and $422 \mathrm{~nm}$ for the aforementioned $\mathrm{SiO}_{2}$ samples at $\mathrm{pH} 7.5$. Under the assumption that the photoreduction of $\mathrm{U}(\mathrm{VI})$ to $\mathrm{U}(\mathrm{IV})$ is not the major cause of the decrease in the luminescence intensities observed for the $\mathrm{U}(\mathrm{VI})-\mathrm{SiO}_{2}$ system, another mechanism referred to as laser-induced thermal desorption (LITD) was studied for the first time to the best of the knowledge of the authors. Quantitative analysis of the desorbed $\mathrm{U}(\mathrm{VI})$ was performed to verify that LITD occurred during UV laser irradiation. The changes in the luminescence spectra resulting from the UV laser irradiation were examined. The luminescence characteristics of desorbed U(VI) species in the filtrates prepared after UV laser irradiation were also studied.

\section{Materials and Methods}

\subsection{Materials}

Table 1 lists the three different $\mathrm{SiO}_{2}$ powders used in this study. The first is hydrophilic fumed $\mathrm{SiO}_{2}$ with a diameter of a few tens of nanometers (Evonik, Essen, Germany, Aerosil 200; this $\mathrm{SiO}_{2}$ is referred to as 'sample No. 1'). It is a nonporous, amorphous material composed of spherical particles with an SSA of approximately $156 \mathrm{~m}^{2} / \mathrm{g}$. The second is a high-purity grade $\mathrm{SiO}_{2}$ gel with a particle size of 40-63 $\mu \mathrm{m}$ (Sigma-Aldrich, Saint Louis, MO, USA, 227196; this $\mathrm{SiO}_{2}$ is referred to as 'sample No. 2'). The pore size of this $\mathrm{SiO}_{2}$ gel is approximately $6 \mathrm{~nm}\left(0.8 \mathrm{~cm}^{3} / \mathrm{g}\right.$ pore volume) with an SSA of approximately $477 \mathrm{~m}^{2} / \mathrm{g}$. The third is a spherical $\mathrm{SiO}_{2}$ powder with a particle size of $1.5 \mu \mathrm{m}$ and an SSA of approximately $2 \mathrm{~m}^{2} / \mathrm{g}$ (Alfa Aesar, Ward Hill, MA, USA, L16987; this $\mathrm{SiO}_{2}$ is referred to as 'sample No. 3'). For each sample, the SSA was determined using the $\mathrm{N}_{2}$ Brunauer-Emmett-Teller method. The $\mathrm{SiO}_{2}$ sample No. 2 was washed with $1 \mathrm{M} \mathrm{HNO}_{3}$ and Millipore water and dried at $383 \mathrm{~K}$. The other two samples were used as they were received from the manufacturer. Powder XRD analyses (Bruker Corporation, Billerica, MA, USA, D8 Advance) were performed using a diffractometer with $\mathrm{CuK} \alpha$ radiation over the range $10-80^{\circ}(2 \theta)$, step size of $0.01^{\circ}$, and scan rate of $0.3 \mathrm{~s} / \mathrm{step}$. X-ray patterns show that all $\mathrm{SiO}_{2}$ samples used were essentially amorphous (data not shown).

For the $\Gamma$-dependent TRLFS measurements, these samples were employed to prepare a suspension with $m / v$ values of $0.01,0.1$, and $1.0 \mathrm{~g} / \mathrm{L}$. U(VI) adsorption reactions were performed in $50 \mathrm{~mL}$ of mixed solution $\left(0.034,0.34\right.$, and $3.4 \mu \mathrm{M} \mathrm{UO}_{2}{ }^{2+}$ and $\left.0.1 \mathrm{M} \mathrm{NaClO}_{4}\right)$ at $\mathrm{pH}$ 7.5. Samples were prepared by adding known amounts of $\mathrm{SiO}_{2}$ to Millipore water, and reagents were added in the following order: $5.77 \mathrm{M} \mathrm{NaClO}_{4}, 1.5 \mathrm{mM} \mathrm{UO}_{2}{ }^{2+}$ in $1.02 \mathrm{M}$ $\mathrm{HClO}_{4}$, which resulted in a $\mathrm{pH}$ of approximately 4.3. For the $\mathrm{pH}$-dependent TRLFS measurements, the samples at $[\mathrm{U}(\mathrm{VI})]=3.4 \mu \mathrm{M}$ and $m / v=1.0 \mathrm{~g} / \mathrm{L}$ were prepared with $\mathrm{pH}$ values in the range of approximately 3.4-7.6. The desired $\mathrm{pH}$ conditions were achieved 
by slowly adding known amounts of $0.1 \mathrm{M} \mathrm{NaOH}\left(\mathrm{CO}_{2}\right.$ free $)$ or $\mathrm{HClO}_{4}$ determined from pre-titration processes. All sample preparations were carried out in an Ar-conditioned glove box with continuous stirring. Samples were further equilibrated in a rotary shaker for two or more days, after which the $\mathrm{pH}$ of the samples was measured using a glass combination electrode (Orion ${ }^{\mathrm{TM}}$ Ross UltraTM, Thermo Scientific, Waltham, MA, USA). As a representative example, the amount of $\mathrm{U}(\mathrm{VI})$ adsorbed to $\mathrm{SiO}_{2}$ sample No. 2 is shown in Figure $\mathrm{S1a}$ as a function of $\mathrm{pH}$. The adsorption edge was observed near $\mathrm{pH} 3.7$ in the $[\mathrm{U}(\mathrm{VI})]$ range of $1-30 \mu \mathrm{M}$. The quantitative analysis of dissolved $\mathrm{U}(\mathrm{VI})$ was performed using inductively coupled plasma-atomic emission spectrometry (ICP-AES, Agilent Technologies, Inc., Santa Clara, CA, USA, 5100 ICP-OES) or inductively coupled plasma-mass spectrometry (ICP-MS, Varian, Inc., Palo Alto, CA, USA, Redtop) to determine the adsorbed $\mathrm{U}(\mathrm{VI})$ amount.

Table 1. $\mathrm{SiO}_{2}$ samples used in this study. Symbols * and ${ }^{* *}$ indicate the value in the specification sheet provided by the manufacturer and the value measured in this study, respectively.

\begin{tabular}{cccccc}
\hline SiO $_{2}$ & Brand & Particle Size & \multicolumn{2}{c}{ SSA (m²) } & Description \\
\hline Sample No. 1 & Evonik Aerosil 200 & $* 5-50 \mathrm{~nm}$ & $* 200$ & $* * 156$ & ${\text { Fumed } \mathrm{SiO}_{2}}^{*}$ \\
\hline Sample No. 2 & Sigma-Aldrich 227196 & $* 40-63 \mu \mathrm{m}$ & $* 550$ & $* * 477$ & $\mathrm{SiO}_{2}$ gel \\
\hline Sample No. 3 & Alfa Aesar L16987 & $* 1.5 \mu \mathrm{m}$ & & $* * 2$ & Spherical SiO $_{2}$ \\
\hline
\end{tabular}

The $\Gamma$ is calculated by dividing the adsorbed U(VI) amount by the surface area (SSA multiplied by $m / v$ ), and the unit is $\mu \mathrm{mol} \mathrm{U} / \mathrm{m}^{2}$ [25-27]. High SSA $\mathrm{SiO}_{2}$ samples with $\Gamma$ of approximately $0.0007-1.526 \mu \mathrm{mol} \mathrm{U} / \mathrm{m}^{2}$ were prepared by adjusting $m / v$ to $0.01-1.0 \mathrm{~g} / \mathrm{L}$ at initial $[\mathrm{U}(\mathrm{VI})]$ values of $0.34-3.4 \mu \mathrm{M}$. Low $\mathrm{SSA} \mathrm{SiO}_{2}$ samples with $\Gamma$ of approximately $0.017-1.7 \mu \mathrm{mol} \mathrm{U} / \mathrm{m}^{2}$ were prepared by adjusting [U(VI)] to $0.034-3.4 \mu \mathrm{M}$ at $m / v=1.0 \mathrm{~g} / \mathrm{L}$. The $\mathrm{U}(\mathrm{VI})$ adsorbed $\mathrm{SiO}_{2}$ sample (3 $\mathrm{mL}$ aliquot) was withdrawn from $50 \mathrm{~mL}$ of suspended solution and transferred to a quartz cell (Hellma Analytics QS 111-10-40) for the TRLFS experiment. The remaining samples were stored in a glove box for a long time and then used again when necessary to investigate the ageing effect as the reaction time of $\mathrm{U}(\mathrm{VI})$ and $\mathrm{SiO}_{2}$ elapsed. In order to observe the change in the distribution of $\mathrm{U}(\mathrm{VI})$ surface species, the luminescence spectral shapes were monitored as a function of reaction time for up to 16 months, and were compared to those of fresh samples.

Nearly $100 \%$ adsorption of $\mathrm{U}(\mathrm{VI})$ was confirmed before UV laser irradiation to examine the $\lambda_{\text {ex }}$-dependent luminescence properties. As soon as the laser irradiation was complete, each $\mathrm{SiO}_{2}$ sample was centrifuged for $30 \mathrm{~min}$ at $18,000 \mathrm{rpm}$ (relative centrifugal force value of around $22,100 \times g$ ). The supernatants were then filtered using $0.45 \mu \mathrm{m}$ syringe filters for quantitative analysis of the dissolved $\mathrm{U}(\mathrm{VI})$ in the filtrates.

\subsection{Laser Spectroscopic Apparatus}

Three different laser systems were used in the TRLFS study. Pulsed Nd:YAG lasers (Continuum, Milpitas, CA, USA, Minilite) at $266 \mathrm{~nm}$ and $355 \mathrm{~nm}$ (Continuum, Milpitas, CA, USA, Surelite) and an optical parametric oscillator at $422 \mathrm{~nm}$ (OPOTEK, Inc., Carlsbad, CA, USA, Vibrant B) were used as the excitation light sources. The laser pulse energy and laser beam profile were measured using an energy meter (Coherent, EPM 2000 with J25LP-MB detector) and a laser beam profiler (Newport, LBP-1), respectively. All lasers were operated at a repetition rate of $10 \mathrm{~Hz}$, and the laser beam diameters $\left(1 / e^{2}\right)$ were approximately $2.5 \mathrm{~mm}$. The pulse energy fluctuations for 5000 laser pulses were within about 3\% (266 nm, $355 \mathrm{~nm})$ and $8 \%(422 \mathrm{~nm})$, and laser pulse energy was monitored before and after measurement. The laser beam passed through the quartz cell, which was located inside the temperature-controlled cuvette holder (Quantum Northwest Turret 4). The sample cell temperature remained constant at $296 \mathrm{~K}$ (room temperature), and the $\mathrm{SiO}_{2}$ suspension was stirred with a stirring bar during measurements. The luminescence perpendicular to the direction of propagation of the laser beam was guided using an optical 
fiber bundle (cross-section of $2 \times 8 \mathrm{~mm}^{2}, 345$ fibers). The output of the optical fiber bundle was connected to a spectrograph (Andor Technology, Belfast, Northern Ireland, SR-303i). TRLFS signals of U(VI) species were recorded by accumulating 100 laser pulses using a gated intensified charge-coupled device (ICCD, Andor Technology, Belfast, Northern Ireland, DH-720/18U-03 iStar 720D). All spectra were measured using a constant gate width $\left(t_{\mathrm{w}}\right)$ of $1000 \mu \mathrm{s}$ and varying gate delay time $\left(t_{\mathrm{d}}\right)$. The quantum efficiency of the ICCD, which varied for different wavelengths, was corrected in the luminescence spectra. Figure S1b of the Supplementary Materials shows the schematic diagram of the experimental setup for TRLFS. Photos of the cuvette holder and sample suspension are also included in Figure S1b.

\section{Results and Discussion}

\subsection{Surface Coverage-Dependent Luminescence Properties}

All data presented in this subsection were measured at $\lambda_{\mathrm{ex}}=266 \mathrm{~nm}$ and a laser pulse energy of $0.1 \mathrm{~mJ}$. Before measuring the $\Gamma$-dependent luminescence properties, $\mathrm{pH}$-dependent luminescence spectra were measured from the high SSA sample No. 1 at $[\mathrm{U}(\mathrm{VI})]=3.4 \mu \mathrm{M}$ and $m / v=1.0 \mathrm{~g} / \mathrm{L}$ as a function of $\mathrm{pH}$. Nearly $100 \%$ adsorption of $\mathrm{U}(\mathrm{VI})$ was observed above $\mathrm{pH}$ 5.0, as shown in Figure S1a. The adsorbed quantity of U(VI) was approximately $70 \%$ at $\mathrm{pH} 4.0$, and the rest existed in the form of aqueous species. For the luminescence measurement of $\mathrm{U}(\mathrm{VI})$ surface species at $\mathrm{pH} 4.0$, the aqueous $\mathrm{U}(\mathrm{VI})$ species were removed by centrifugation, after which the separated $\mathrm{SiO}_{2}$ particles were resuspended in a fresh background $\mathrm{NaClO}_{4}$ solution with a $\mathrm{pH}$ and an ionic strength identical to the original ones but without $\mathrm{U}(\mathrm{VI})$. The data in Figure 1 show the luminescence spectra, which were normalized by the intensity of the strongest peak.

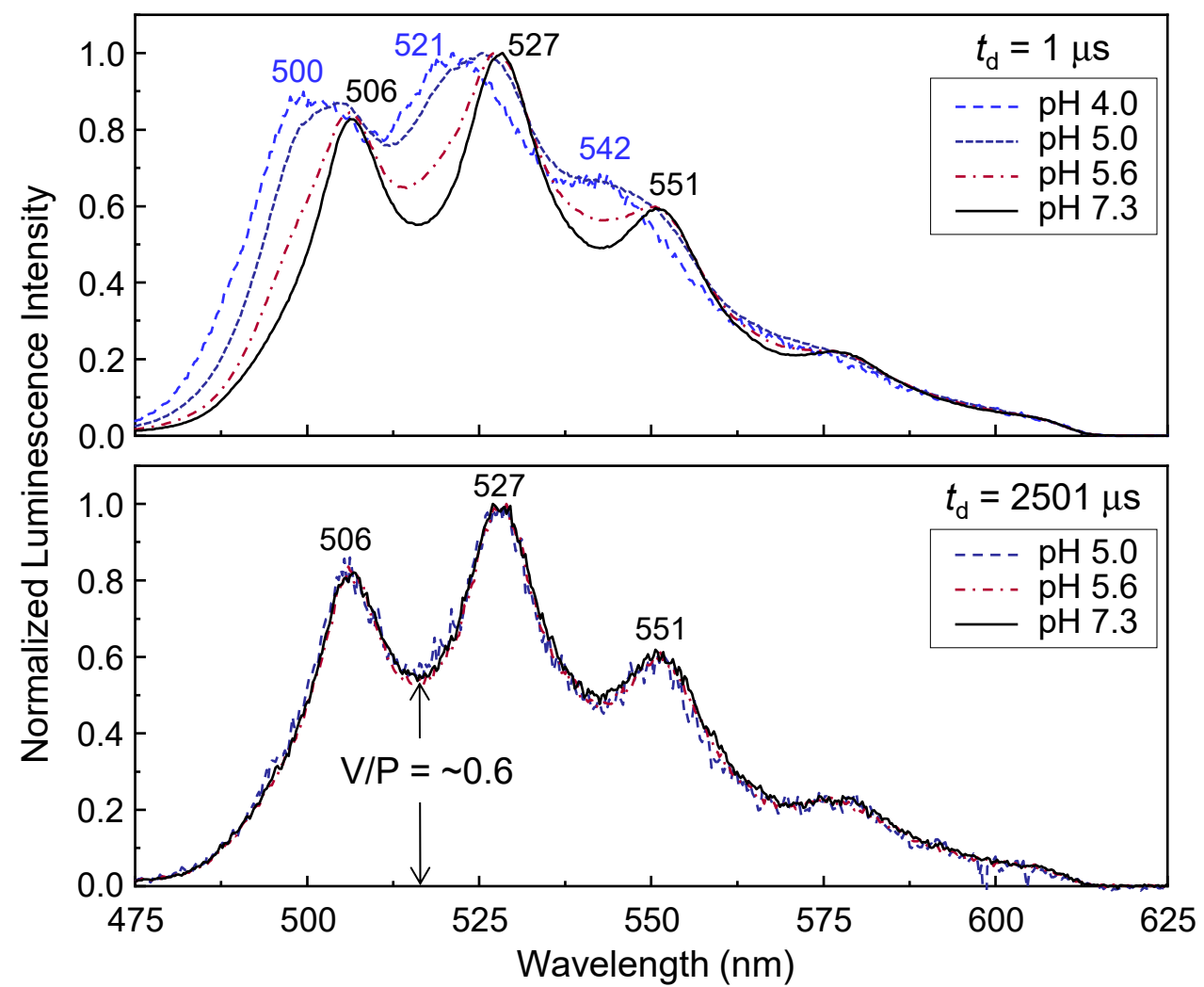

Figure 1. Normalized luminescence spectra of $\mathrm{U}(\mathrm{VI})$ adsorbed onto the high $\mathrm{SSA} \mathrm{SiO}_{2}$ (sample No. 1, $[\mathrm{U}(\mathrm{VI})]=3.4 \mu \mathrm{M}, m / v=1.0 \mathrm{~g} / \mathrm{L}$ ) under various $\mathrm{pH}$ conditions. The (upper) and (lower) panels were measured at $t_{\mathrm{d}}=1 \mu$ s and $2501 \mu \mathrm{s}$, respectively. 
The peak wavelength values are expressed in Arabic numerals in Figure 1. Two U(VI) surface species, $\equiv \mathrm{SiO}_{2} \mathrm{UO}_{2}$ and $\equiv \mathrm{SiO}_{2}\left(\mathrm{UO}_{2}\right) \mathrm{OH}^{-}$, were distinguished based on the representative results obtained from the $\mathrm{SiO}_{2}$ samples at similar conditions of $[\mathrm{U}(\mathrm{VI})]=1.0 \mu \mathrm{M}$ and $m / v=1.0 \mathrm{~g} / \mathrm{L}$ [17]. In the upper panel, the spectrum acquired at $\mathrm{pH} 4.0$ is completely controlled by $\equiv \mathrm{SiO}_{2} \mathrm{UO}_{2}$ and the luminescence peaks are located at approximately 500, 521, and $542 \mathrm{~nm}$. The peak maxima are shifted to 506, 527, and $551 \mathrm{~nm}$ at pH 7.3. The shift of peak maxima represents the existence of the U(VI)-hydroxo surface species [13,17,18,21-23]. The spectra measured under different $\mathrm{pH}$ values ( $\mathrm{pH} 5.0$ and 5.6) in the upper panel demonstrate the transition of the dominant species from acidic to near-neutral $\mathrm{pH}$ conditions.

In the lower panel of Figure 1, the spectra acquired at $t_{\mathrm{d}}=2501 \mu \mathrm{s}$ can be considered the luminescence of the U(VI)-hydroxo surface species alone because the spectral overlap between these species is eliminated because of the much shorter luminescence lifetime of $\equiv \mathrm{SiO}_{2} \mathrm{UO}_{2}$, as discussed later in association with spectral decomposition using the luminescence lifetime. To compare the luminescence spectral shapes in more detail, we defined the valley-to-peak $(\mathrm{V} / \mathrm{P})$ intensity ratio as the luminescence intensity of the first valley versus the intensity of the strongest peak, designated by an arrow in Figure 1. In the lower panel, there are no significant differences between the $\mathrm{V} / \mathrm{P}$ intensity ratios measured at various $\mathrm{pH}$ values. In addition, the peak wavelengths and spectral shapes remain unchanged for $t_{\mathrm{d}}$ in the range of 2001-3001 $\mu$ s. Thus, the spectra measured under the long- $t_{\mathrm{d}}$ condition were generated by a unique $\mathrm{U}(\mathrm{VI})$-hydroxo surface species. The change in the $\mathrm{V} / \mathrm{P}$ intensity ratio at various $\mathrm{pH}$ values results from the overlap of the luminescence spectra generated by multiple U(VI) species, as shown in the upper panel of Figure 1. An increase in $\mathrm{pH}$ leads to a lower $\mathrm{V} / \mathrm{P}$ intensity ratio. This result is ascribed to the increase in the relative quantity of $U(V I)$-hydroxo surface species with $\mathrm{pH}$, which shows a highly resolved spectrum at neutral $\mathrm{pH}$ values. In Figure S2 of the Supplementary Materials, the luminescence spectra measured for the other high SSA SiO 2 (sample No. 2, $[\mathrm{U}(\mathrm{VI})]=3.4 \mu \mathrm{M}, m / v=1.0 \mathrm{~g} / \mathrm{L}$ ) at various $\mathrm{pH}$ values show very similar shapes to those displayed in Figure 1.

The spectral shape with a V/P intensity ratio close to 0.6 at the near-neutral $\mathrm{pH}$ in Figure 1 is significantly different from those observed in other studies $[18,23]$. For example, Chisholm-Brause et al. [18] reported a V/P intensity ratio of approximately 0.9 (judging by Figure 1 in Chisholm-Brause et al.; the V/P intensity ratio was not given specifically) in the luminescence spectrum under the conditions of $\mathrm{pH} 8$ and $\Gamma=3.846 \mu \mathrm{mol} \mathrm{U} / \mathrm{m}^{2}$ (initial $[\mathrm{U}(\mathrm{VI})]=9 \mu \mathrm{M}, m / v=0.013 \mathrm{~g} / \mathrm{L}$, and SSA $=180 \mathrm{~m}^{2} / \mathrm{g}$ ) for the same $\mathrm{SiO}_{2}$ sample (Aerosil 200) used in this study. They predicted that the overall distribution consisted of about $20 \% \equiv \mathrm{SiO}_{2} \mathrm{UO}_{2}$ and $80 \% \equiv \mathrm{SiO}_{2}\left(\mathrm{UO}_{2}\right)_{3}(\mathrm{OH})_{5}{ }^{-}$based on the thermodynamic model predictions depicted in Figure 3 of McKinley et al. [1]. On the other hand, Gabriel et al. [17] observed a V/P intensity ratio of approximately 0.7 (judging by Figure 5 in Gabriel et al.; the $\mathrm{V} / \mathrm{P}$ intensity ratio was not given specifically) under the conditions of $\mathrm{pH} 7.7$ and $\Gamma=0.006 \mu \mathrm{mol} \mathrm{U} / \mathrm{m}^{2}$ (initial $[\mathrm{U}(\mathrm{VI})]=1 \mu \mathrm{M}, \mathrm{m} / v=1.0 \mathrm{~g} / \mathrm{L}$, and SSA $=169 \mathrm{~m}^{2} / \mathrm{g}$ ) for the same $\mathrm{SiO}_{2}$ sample. They observed that the overall distribution consisted entirely of $\equiv \mathrm{SiO}_{2}\left(\mathrm{UO}_{2}\right) \mathrm{OH}^{-}$under the high $m / v$ condition. Considering the $[\mathrm{U}(\mathrm{VI})]$ and $m / v$ values used in these studies $[17,18]$, it seems plausible that an increase in $\Gamma$ leads to a higher $V / P$ intensity ratio under near-neutral $\mathrm{pH}$ conditions.

The $\Gamma$-dependent luminescence spectra were measured from the high SSA sample No. 1 at pH 7.5. Six samples with different $[\mathrm{U}(\mathrm{VI})]$ and $m / v$ conditions were prepared, as shown in the legends of Figure 2. Among these samples, the adsorbed U(VI) amount of the sample with the highest $\Gamma([\mathrm{U}(\mathrm{VI})]=3.4 \mu \mathrm{M}, m / v=0.01 \mathrm{~g} / \mathrm{L})$ was about $70 \%$, and all other samples showed an adsorbed U(VI) amount of $98 \%$ or more. The data in Figure 2 represent the normalized luminescence spectra measured at $\mathrm{pH} 7.5$, and all spectra were acquired at $t_{\mathrm{d}}=1 \mu \mathrm{s}$. The upper and lower panels in Figure 2 were measured at $[\mathrm{U}(\mathrm{VI})]=0.34$ and $3.4 \mu \mathrm{M}$, respectively. The normalized luminescence spectra obviously change in shape as $m / v$ changes, even when $[\mathrm{U}(\mathrm{VI})]$ remains the same. An increase in $m / v$ leads to a lower V/P intensity ratio in Figure 2, as expected based on comparison with previous 
studies $[17,18]$. The change in the $\mathrm{V} / \mathrm{P}$ intensity ratio becomes more pronounced at higher $[\mathrm{U}(\mathrm{VI})]$, as shown in the lower panel of Figure 2.

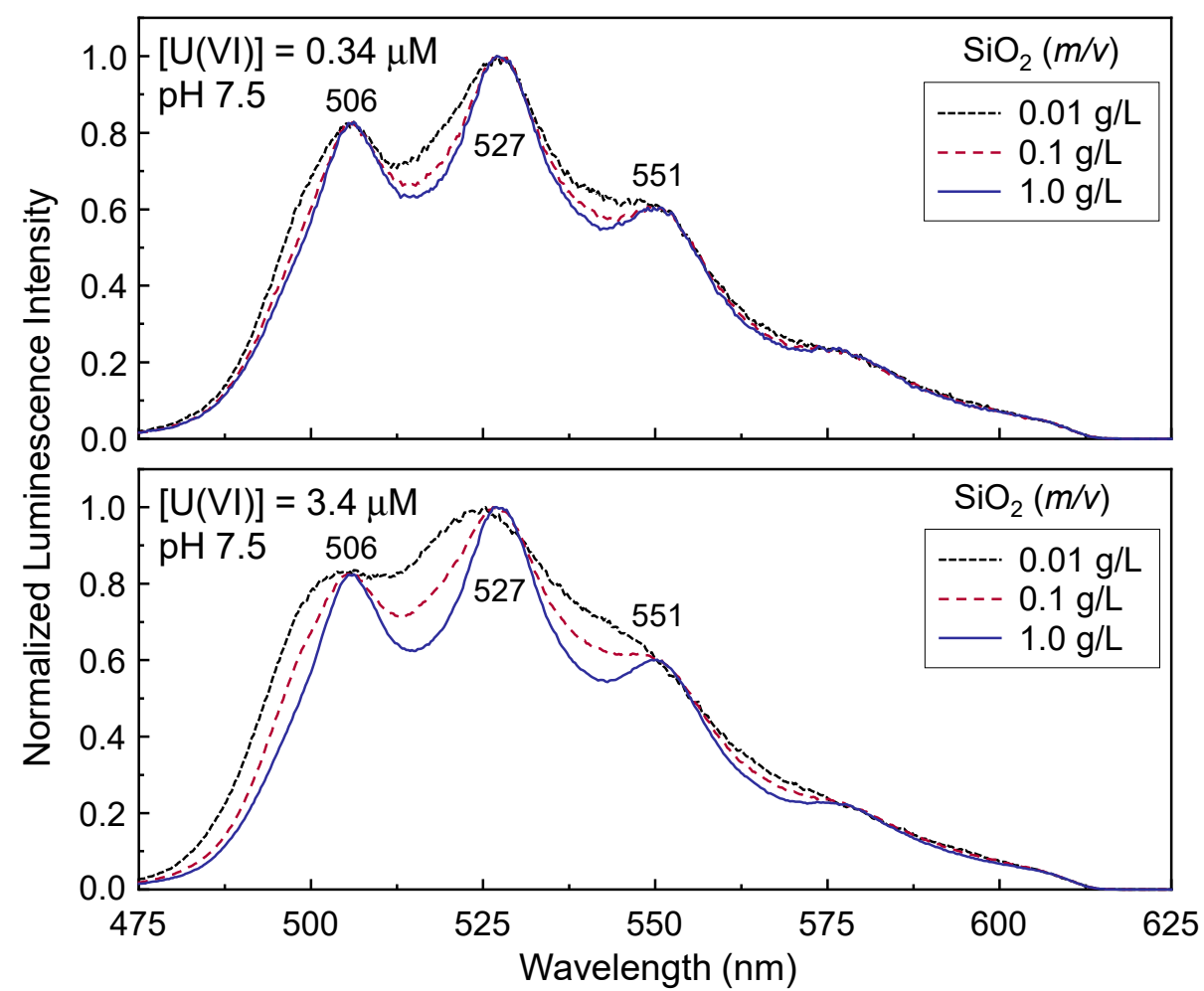

Figure 2. Normalized luminescence spectra of $U(V I)$ adsorbed onto the high SSA sample (sample No. 1, pH 7.5) under various $[\mathrm{U}(\mathrm{VI})] /(m / v)$ ratios. The spectra were measured at $t_{\mathrm{d}}=1 \mu \mathrm{s}$. The (upper) and (lower) panels were measured at $[\mathrm{U}(\mathrm{VI})]=0.34$ and $3.4 \mu \mathrm{M}$, respectively.

Figure S3 in the Supplementary Materials presents the normalized luminescence spectra derived from the data in Figure 2. Lower $\mathrm{V} / \mathrm{P}$ intensity ratios with narrower spectral widths are observed as [U(VI)] decreases from 3.4 to $0.34 \mu \mathrm{M}$ under the same $m / v$ value in Figure S3a,b. In the case of a sufficiently high $m / v$ condition in Figure S3c, the normalized luminescence spectra show identical spectral shapes with the same V/P intensity ratio when $[\mathrm{U}(\mathrm{VI})]=0.34$ and $3.4 \mu \mathrm{M}$. Similarly, Gabriel et al. observed identical spectral shapes with $[\mathrm{U}(\mathrm{VI})]=0.1$ and $1.0 \mu \mathrm{M}$ at $m / v=1.0 \mathrm{~g} / \mathrm{L}$ [17]. The data in Figure 2 and Figure S3 indicate that the existence of different U(VI) surface species at $\mathrm{pH} 7.5$, and their respective proportions depend on $\Gamma$.

The luminescence lifetimes were also used to obtain information about the adsorbed $\mathrm{U}(\mathrm{VI})$ species on $\mathrm{SiO}_{2}$. Assuming that two U(VI) surface species contribute to the luminescence spectra, the following double exponential decay equation was used [31]:

$$
\ln \{I(t)\}=\ln \left\{a \times \exp \left(-\frac{t}{\tau_{1}}\right)+(1-a) \times \exp \left(-\frac{t}{\tau_{2}}\right)\right\}
$$

where $I(t)$ is the normalized luminescence intensity integrated from 475 to $600 \mathrm{~nm}$, and $a$ and $1-a$ are the relative quantities of short- and long-lived components (called 'species 1 ' and 'species 2 ') with luminescence lifetimes of $\tau_{1}$ and $\tau_{2}$, respectively. Figure 3 shows the fitting results measured from the samples at $\mathrm{pH} 7.5$ used in Figure $2 . t_{\mathrm{d}}$ varies from 1 to $3001 \mu \mathrm{s}$ with a gate delay step of $50 \mu \mathrm{s}$. The symbols and lines in Figure 3 represent the normalized luminescence intensities on the natural logarithmic scale and the results of fitting the data to Equation (1) using Origin 9.5, respectively.

Table 2 summarises the luminescence lifetimes and relative quantities of species 1 and 2. The coefficients of determination $\left(\mathrm{R}^{2}\right)$ and the residual sum of squares (RSS) are also listed 
for all fits. $\tau_{2}$ was provided as a 'known' value and was determined as shown in Figure S4 in the Supplementary Materials. The normalized luminescence spectra remain unchanged for $t_{\mathrm{d}}$ in the range of 2001-3001 $\mu \mathrm{s}$, as shown in Figure S4a. This result means that $\tau_{2}$ can be determined by fitting the luminescence intensities measured at $t_{\mathrm{d}}=2001-3001 \mu$ s to the linear regression, depicted as the solid line in Figure S4b.

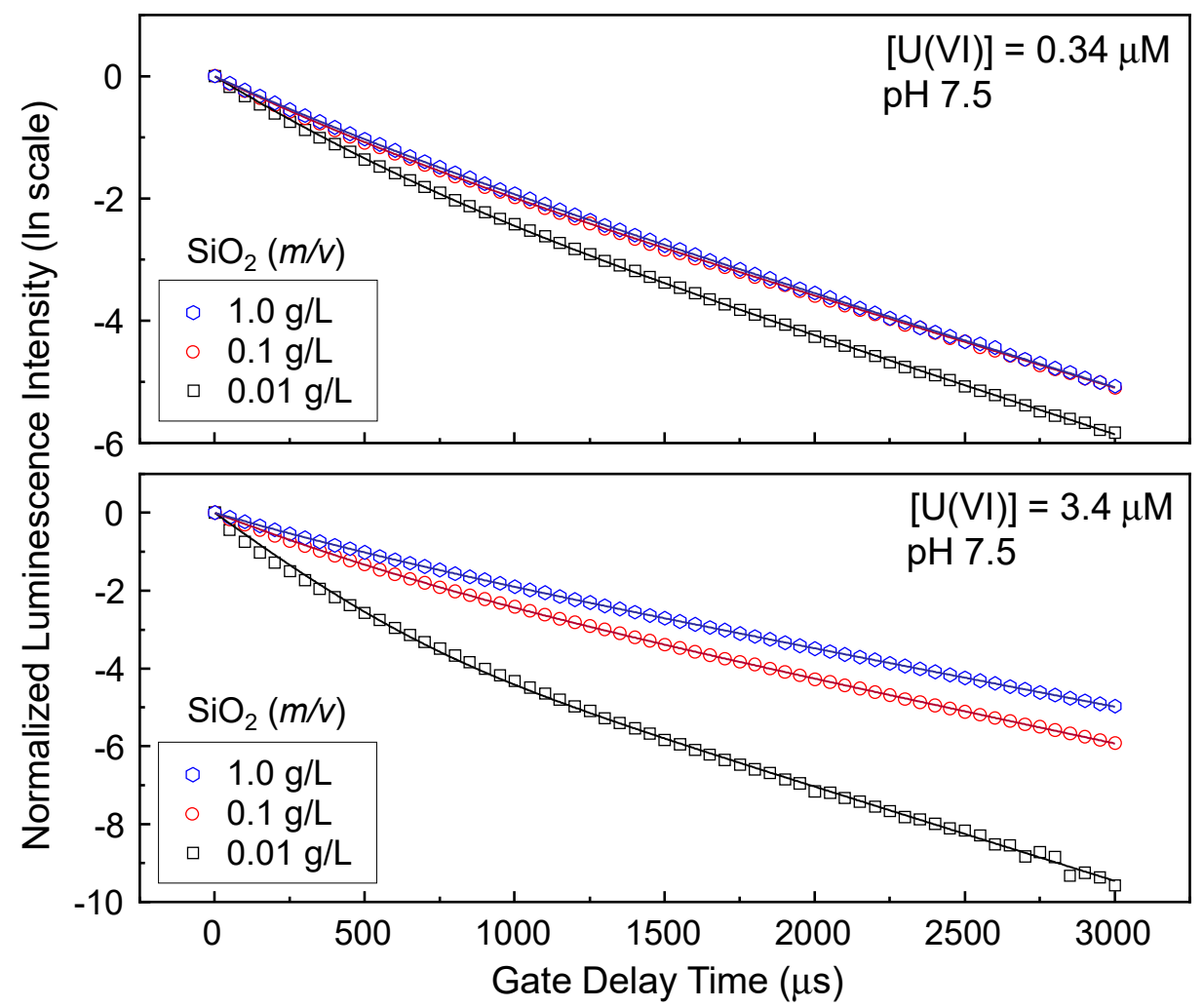

Figure 3. Luminescence lifetimes of $U(V I)$ surface species measured from the samples used to obtain Figure 2. The kinetic mode of the ICCD was utilized with $t_{\mathrm{d}}=1-3001 \mu \mathrm{s}$ and a gate delay step of $50 \mu \mathrm{s}$. The symbols represent the normalized luminescence intensity on the natural logarithmic scale for $\mathrm{U}(\mathrm{VI})$ surface species. The solid lines represent the fitting data calculated using Equation (1).

Table 2. Luminescence lifetimes and relative quantities of species 1 and 2 measured from the high $\mathrm{SSA} \mathrm{SiO}_{2}$ (sample No. 1, pH 7.5). These values were determined using the data shown in Figures 2 and $3 . R^{2}$ and RSS values are listed in the last column.

\begin{tabular}{|c|c|c|c|c|c|c|c|}
\hline \multicolumn{2}{|c|}{ Samples } & \multirow{2}{*}{$\Gamma\left(\mu \mathrm{mol} \mathrm{U} / \mathrm{m}^{2}\right)$} & \multicolumn{2}{|c|}{ Species 1} & \multicolumn{2}{|c|}{ Species 2} & \multirow{2}{*}{$\mathrm{R}^{2}(\mathrm{RSS})$} \\
\hline$[\mathrm{U}(\mathrm{VI})](\mu \mathrm{M})$ & $m / v(\mathrm{~g} / \mathrm{L})$ & & $a$ & $\tau_{1}(\mu \mathrm{s})$ & $1-a$ & $\tau_{2}(\mu \mathrm{s})$ & \\
\hline 0.34 & 1.0 & 0.002 & 0.412 & 311 & 0.588 & 658 & $\begin{array}{c}0.99995 \\
(0.00648)\end{array}$ \\
\hline 3.4 & 1.0 & 0.021 & 0.406 & 305 & 0.594 & 671 & $\begin{array}{c}0.99998 \\
(0.00292)\end{array}$ \\
\hline 0.34 & 0.1 & 0.021 & 0.467 & 298 & 0.533 & 671 & $\begin{array}{c}0.99995 \\
(0.00614)\end{array}$ \\
\hline 3.4 & 0.1 & 0.217 & 0.637 & 275 & 0.363 & 610 & $\begin{array}{c}0.99993 \\
(0.01177)\end{array}$ \\
\hline 0.34 & 0.01 & 0.217 & 0.664 & 277 & 0.336 & 629 & $\begin{array}{c}0.99986 \\
(0.02347)\end{array}$ \\
\hline 3.4 & 0.01 & 1.526 & 0.893 & 168 & 0.107 & 415 & $\begin{array}{c}0.99891 \\
(0.44745)\end{array}$ \\
\hline
\end{tabular}


The data listed in Table 2 are plotted as a function of $\Gamma$ in Figure 4. Interestingly, a change in luminescence lifetime is observed as $\Gamma$ changes, as shown in the upper panel of Figure $4 . \tau_{1}$ and $\tau_{2}$ change from approximately 170 and $400 \mu \mathrm{s}$, respectively, and converge at approximately 310 and $670 \mu$ in the $\Gamma$ region below $0.01 \mu \mathrm{mol} \mathrm{U} / \mathrm{m}^{2}$. The lower panel of Figure 4 shows the relative quantities of species 1 and 2 . The quantity of species 1 ( $a$ in Equation (1)) increases with increasing $\Gamma$, and vice versa for species $2((1-a)$ in Equation (1)).
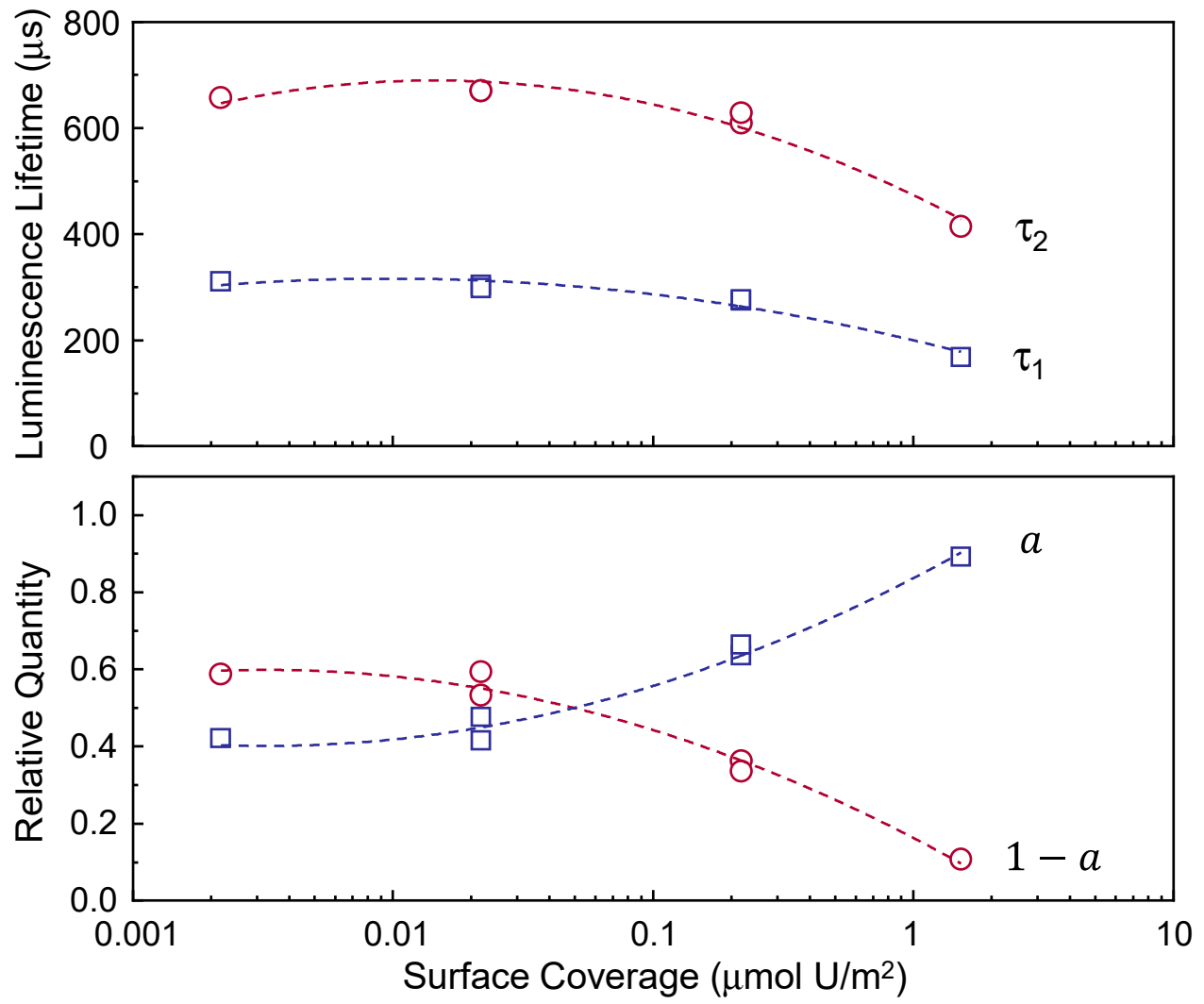

Figure 4. Luminescence lifetimes and relative quantities in Table 2 as a function of $\Gamma$. Blue rectangle and red circle represent the characteristics of species 1 and species 2 , respectively. The dashed lines represent the results of fitting the data to the polynomial equation $\left(y=B_{1} \cdot x+B_{2} \cdot x^{2}+\right.$ intercept) for easy observation of the increasing and decreasing behaviours of the data.

The decomposition results from the three spectra in the lower panel of Figure 2 are presented in Figure 5. The luminescence spectra of species 1 were resolved by subtracting the corrected spectra of species 2 from the corresponding luminescence spectra taken at $t_{\mathrm{d}}=1 \mu \mathrm{s}[22,41,42]$. The corrected spectra of species 2 at $t_{\mathrm{d}}=1 \mu \mathrm{s}$ were obtained from the luminescence spectra acquired at $t_{\mathrm{d}}=2501 \mu \mathrm{s}$ by compensating for the exponential decay of the luminescence intensity with a lifetime $\tau_{2}$, as listed in Table 2 . Different luminescence peak positions in the luminescence spectra of species 1 are observed with changing $\Gamma$, depicted as solid lines in the upper panel of Figure 5. The peak positions of species 1 measured at $\Gamma \approx 1.526 \mu \mathrm{mol} \mathrm{U} / \mathrm{m}^{2}$ are blue-shifted compared to those measured at lower $\Gamma$ values $\left(\Gamma \approx 0.217\right.$ and $\left.0.021 \mu \mathrm{mol} \mathrm{U} / \mathrm{m}^{2}\right)$. 


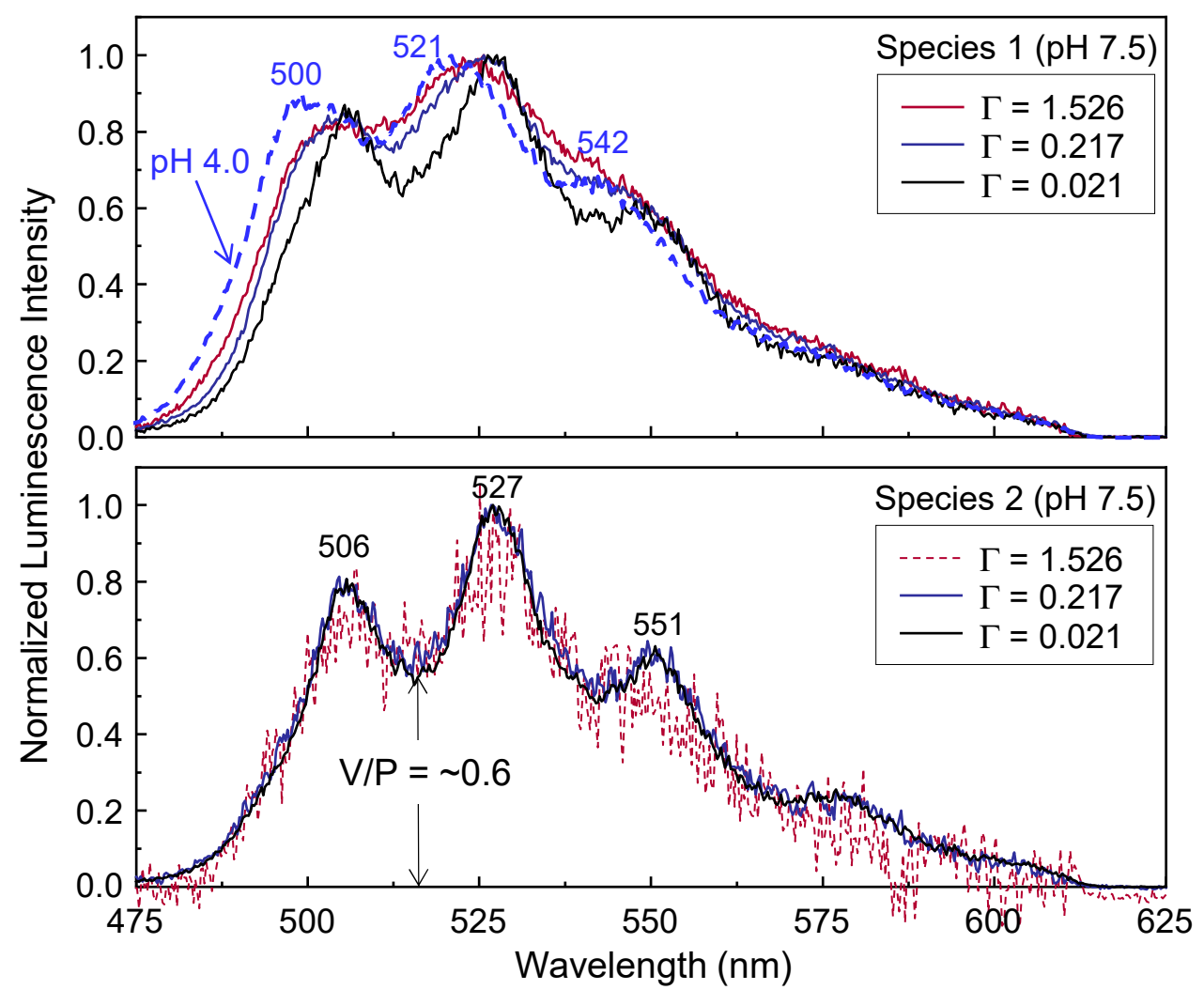

Figure 5. The upper panel represents the normalized luminescence spectra of species 1 (solid lines, pH 7.5) obtained by decomposition of the luminescence spectra displayed in the lower panel of Figure 2. Decomposition was performed using the manual subtraction method. The dashed line measured at $\mathrm{pH} 4.0$ represents the normalized luminescence spectrum of $\equiv \mathrm{SiO}_{2} \mathrm{UO}_{2}$. Normalized luminescence spectra of species 2 measured at $t_{\mathrm{d}}=2501 \mu$ s are displayed in the lower panel.

The spectral shapes of species 2 taken at $t_{\mathrm{d}}=2501 \mu \mathrm{s}$ in the lower panel of Figure 5 are almost identical for all samples with different $\Gamma$ values. Thus, species 2 may have a similar nature for all samples. The peak positions of species 2 in the lower panel imply that species 2 is the $\mathrm{U}(\mathrm{VI})$-hydroxo surface species. Considering the $[\mathrm{U}(\mathrm{VI})]$ level of $0.34-3.4 \mu \mathrm{M}$ used in this study, species 2 likely represents $\equiv \mathrm{SiO}_{2}\left(\mathrm{UO}_{2}\right) \mathrm{OH}^{-}$[17].

The question is whether the short-lived species 1 represents $\equiv \mathrm{SiO}_{2} \mathrm{UO}_{2}$, which is known to be the predominant species in the acidic $\mathrm{pH}$ range, or another species existing in the near-neutral $\mathrm{pH}$ range. The upper panel of Figure 5 compares the spectra of species 1 with the spectrum of $\equiv \mathrm{SiO}_{2} \mathrm{UO}_{2}$ (dashed line) measured from the $\mathrm{SiO}_{2}$ sample at $\mathrm{pH} 4.0$ (the same spectrum shown in Figure 1). It is clearly observed that the luminescence peak positions of species 1 measured at $\mathrm{pH} 7.5$ do not exactly coincide with those of $\equiv \mathrm{SiO}_{2} \mathrm{UO}_{2}$ measured at $\mathrm{pH}$ 4.0.

PARAFAC analysis was also applied to decompose the spectra in Figure 2. The decomposition with two spectral components converges well with high core-consistency value of $99.8 \%$. However, analysis using the three spectral components resulted in a lack of core-consistency. Figure S5 shows the results of PARAFAC analysis obtained from the six spectra in Figure 2. Similar to the results in Figure 5, species 1 shows the peak maxima shifted in the longer wavelength direction compared to those of $\equiv \mathrm{SiO}_{2} \mathrm{UO}_{2}$. In the lower panel of Figure S5, the luminescence lifetimes of the decomposed spectra were determined to be $\tau_{1}=219$ and $\tau_{2}=617 \mu \mathrm{s}$, respectively. However, these values obtained from the five datasets, excluding the highest $\Gamma$, changed to $\tau_{1}=306$ and $\tau_{2}=641 \mu \mathrm{s}$, respectively (data not shown). This result also suggests that the luminescence characteristics of the $\mathrm{U}(\mathrm{VI})$ surface species depend on the $\Gamma$ values, as described in Table 2 and Figure 4 . In order to directly present $\Gamma$-dependent luminescence characteristics, it is preferred to explain 
the decomposition results extracted by the manual subtraction method rather than the PARAFAC analysis.

In addition, species 1 shows unstable complexation properties. For example, the luminescence spectrum measured at $t_{\mathrm{d}}=1 \mu \mathrm{s}$ in Figure S6a reveals a $\mathrm{V} / \mathrm{P}$ intensity ratio of approximately 0.64 immediately after sample preparation (in the so-called 'fresh sample'). After 16 months of reaction time, the $\mathrm{V} / \mathrm{P}$ intensity ratio changes to approximately 0.55 , as shown by the dotted line in Figure S6a, because species 1 (relative quantity of approximately $41 \%$ in the fresh sample, as shown in the first row of Table 2) almost disappears for the aged sample, which was stored in an Ar-filled glove box. In contrast, the quantity of species 2 (relative quantity of approximately $59 \%$ in the fresh sample, as shown in the first row of Table 2) increases with increasing ageing time at the expense of species 1. Consequently, the luminescence lifetime of the aged sample was determined using a single exponential decay equation ( $\tau_{2}$ only) instead of Equation (1), as shown in Figure S6b. These results imply that species 2 is more strongly bonded to the surface than species 1 . A very similar ageing effect was observed in the previous TRLFS study on the U(VI) surface species adsorbed on the low SSA quartz powders (US Silica, Katy, TX, USA, Min-U-Sil 30, SSA of $1.63 \pm 0.02 \mathrm{~m}^{2} / \mathrm{g}$ ) by Ilton et al. [22]. They reported that the long-term contact of $\mathrm{U}(\mathrm{VI})$ with $\mathrm{SiO}_{2}$ under neutral $\mathrm{pH}$ conditions resulted in a change in the species distribution and proposed a monodentate $\mathrm{U}(\mathrm{VI})$ surface complex as unstable species 1 because of the weak bonding nature to the surface. The increase in the relative quantity of species 2 was attributed to the formation of multidentate $\mathrm{U}(\mathrm{VI})$ surface complexes [22] based on the molecular dynamic modelling of hydroxylated-U(VI) adsorption to low-index quartz surfaces [43].

At present, the TRLFS results alone do not provide sufficient information for the chemical speciation of species 1 observed at $\mathrm{pH}$ 7.5. A more in-depth study is needed to elucidate whether different peak positions of species 1 compared with those of $\equiv \mathrm{SiO}_{2} \mathrm{UO}_{2}$ indicate another different $\mathrm{U}(\mathrm{VI})$ surface species existing in the near-neutral $\mathrm{pH}$ range or a $\Gamma$-dependent drift of the luminescence properties of $\equiv \mathrm{SiO}_{2} \mathrm{UO}_{2}$.

The identical spectral shapes in the lower panel of Figure 5 with the $\Gamma$-dependent luminescence lifetimes of the species 2 listed in Table 2 indicate that the luminescence properties are significantly influenced by the surface parameters of $\mathrm{SiO}_{2}$. Multidentate $\mathrm{U}(\mathrm{VI})-\mathrm{SiO}_{2}$ surface complexes are most likely formed under low $\Gamma$ conditions due to the presence of high affinity sites, which are significant when smaller ratios of $\mathrm{U}(\mathrm{VI})$ loading to surface sites are involved. Similarly, a bridging bidentate configuration with U(VI) binding to the two surface sites was suggested as the surface species under low $\mathrm{U}(\mathrm{VI})$ loading conditions $[9,10,44]$.

In this regard, it is of interest to examine the $\mathrm{pH}$-dependent luminescence lifetimes of $\mathrm{U}(\mathrm{VI})$ surface species with a fixed $[\mathrm{U}(\mathrm{VI})] /(\mathrm{m} / \mathrm{v}]$ ratio because the probability of having two or more deprotonated adjacent sites increases with increasing $\mathrm{pH}$ [22]. Figure 6 summarizes the luminescence lifetimes determined from 34 fresh samples (sample No. 1, $[m / v]=1.0 \mathrm{~g} / \mathrm{L},[\mathrm{U}(\mathrm{VI})]=3.4 \mu \mathrm{M})$ under various $\mathrm{pH}$ conditions in the range of 3.4-7.6. The luminescence lifetime was determined to be $\tau_{\mathrm{s}}=233 \pm 16 \mu \mathrm{s}$ for the samples in the $\mathrm{pH}$ range of 3.4-4.1, where only the luminescence spectra of the $\equiv \mathrm{SiO}_{2} \mathrm{UO}_{2}$ species appear. The lifetimes of species 1 and 2 were determined to be $\tau_{1}=296 \pm 17 \mu \mathrm{s}$ and $\tau_{2}=653 \pm 12 \mu \mathrm{s}$, respectively, in the $\mathrm{pH}$ range of 7.0-7.6. Although the spectral shapes of species 2 are almost identical, as shown in the lower panel of Figure 1, the luminescence lifetimes vary in the $\mathrm{pH}$ range of 4.5-7.6, as depicted by the dashed line in Figure 6, which can be seen even with the naked eye. The lifetime increases from approximately $500 \mu$ s near $\mathrm{pH} 4.5$ and converges to a constant value at near-neutral $\mathrm{pH}$. The $\mathrm{pH}$-dependent luminescence lifetimes of $\mathrm{U}(\mathrm{VI})$ surface species at a fixed $[\mathrm{U}] /[\mathrm{m} / \mathrm{v}]$ ratio in Figure 6 are in accordance with the $\Gamma$-dependent luminescence lifetimes at fixed $\mathrm{pH}$ in Figure 4 . These observations are major experimental results that can explain the cause of the inconsistent luminescence lifetimes reported in previous studies, irrespective of whether species 2 represents $\equiv \mathrm{SiO}_{2}\left(\mathrm{UO}_{2}\right) \mathrm{OH}^{-}$ or $\equiv \mathrm{SiO}_{2}\left(\mathrm{UO}_{2}\right)_{3}(\mathrm{OH})_{5}{ }^{-}$. The luminescence lifetimes determined in this study are listed in the last row of Table S1. 


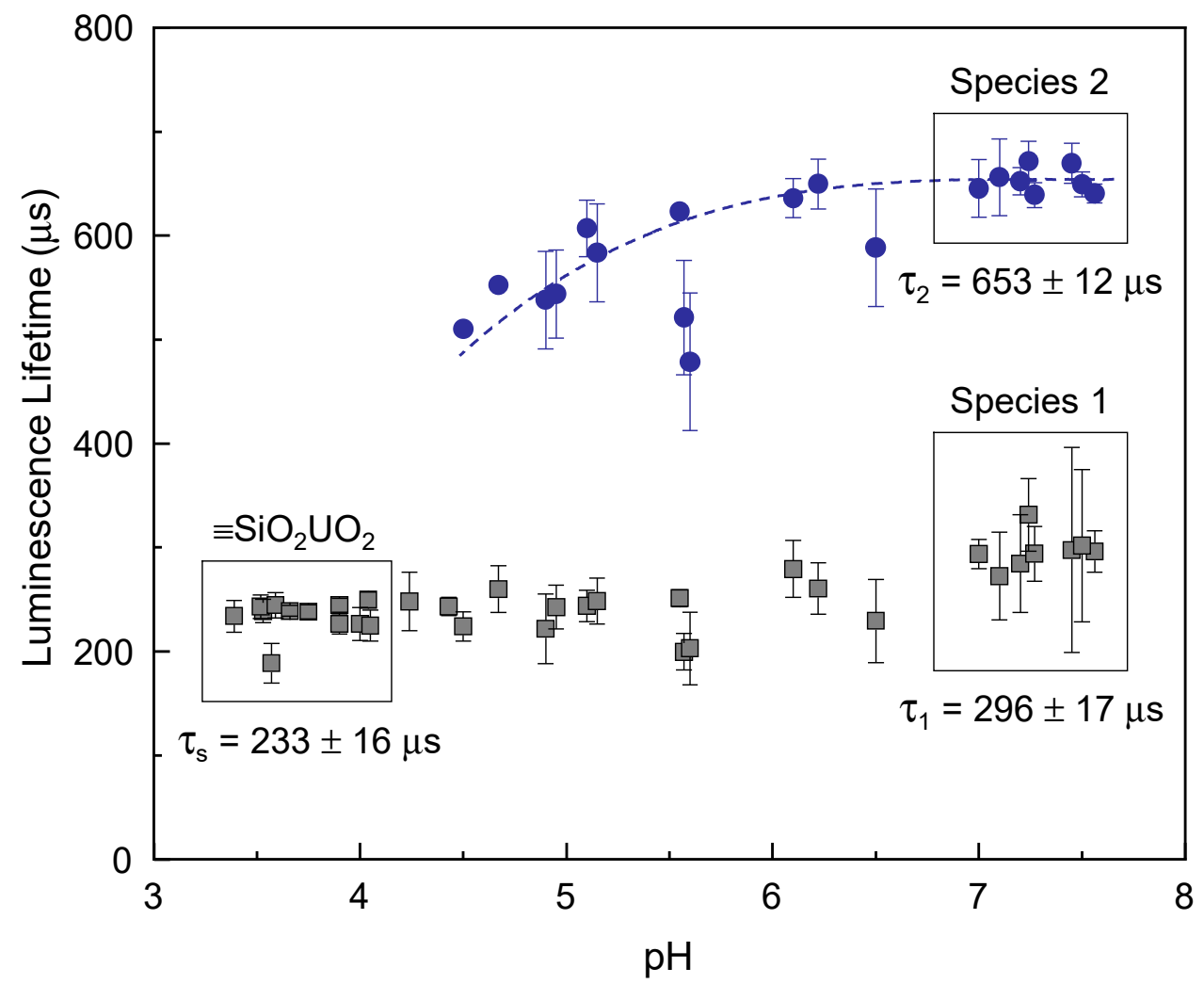

Figure 6. $\mathrm{pH}$-dependent luminescence lifetimes of the $\mathrm{U}(\mathrm{VI})$ surface species determined from 34 samples in the $\mathrm{pH}$ range of 3.4-7.6 at the constant $\Gamma=0.021 \mu \mathrm{mol} \mathrm{U} / \mathrm{m}^{2}$ (sample No. 1 , $m / v=1.0 \mathrm{~g} / \mathrm{L},[\mathrm{U}(\mathrm{VI})]=3.4 \mu \mathrm{M})$.

The $\Gamma$-dependent luminescence properties were examined for the other high SSA $\mathrm{SiO}_{2}$ samples (sample No. 2, pH 7.5), and the results are shown in Figures S7-S9 and Table S2. Although there was a large difference in particle size between $\mathrm{SiO}_{2}$ samples No. 1 and No. 2 (Table 1), very similar trends in the luminescence properties were identified. These results demonstrate that the luminescence properties of the U(VI) surface species on amorphous $\mathrm{SiO}_{2}$ are independent of the particle size. Figures S10 and S11 and Table S3 show the luminescence characteristics measured from the low $\mathrm{SSA} \mathrm{SiO}_{2}$ samples (sample No. 3, pH 7.5). The $\Gamma$-dependent luminescence properties are also clearly observed.

The upper panel in Figure 7 compares the luminescence spectral shapes measured from the high- and low-SSA samples listed in Table 1. Despite the significantly different $m / v$ values $(0.01 \mathrm{~g} / \mathrm{L}$ for sample No. 1 and $1.0 \mathrm{~g} / \mathrm{L}$ for sample No. 3 ), the luminescence spectra resemble each other in a similar $\Gamma$ range (approximately $\Gamma=1.5 \mu \mathrm{mol} \mathrm{U} / \mathrm{m}^{2}$ for fresh sample No. 1 and $\Gamma=1.7 \mu \mathrm{mol} U / \mathrm{m}^{2}$ for fresh sample No. 3 at $\left.[\mathrm{U}(\mathrm{VI})]=3.4 \mu \mathrm{M}\right)$. The luminescence spectrum measured from fresh sample No. 3 shows a V/P intensity ratio of approximately 0.8 . This ratio changes to approximately 0.65 after one year of reaction time, as indicated by the dashed line because the relative quantity of species 2 increases with time. It is observed that the ageing effect changes the luminescence lifetime as well as the spectral shape. As shown in the lower panel of Figure 7, the luminescence lifetimes of both species 1 and 2 increase with increasing ageing time. As a year passed, the relative amount of species 1 decreased from $93 \%$ to $49 \%$, and that of species 2 increased from $7 \%$ to $51 \%$. In a previous study on the ageing effect, Ilton et al. performed TRLFS experiments at liquid He temperature and did not report the lifetime information of the U(VI) surface species; thus, direct comparison of their results with those obtained in this study is not possible [22]. Nevertheless, the data displayed in Figure 7 suggest that the ageing time-dependent luminescence properties result from surface complexes, which evolved toward higher coordination with surface sites. 


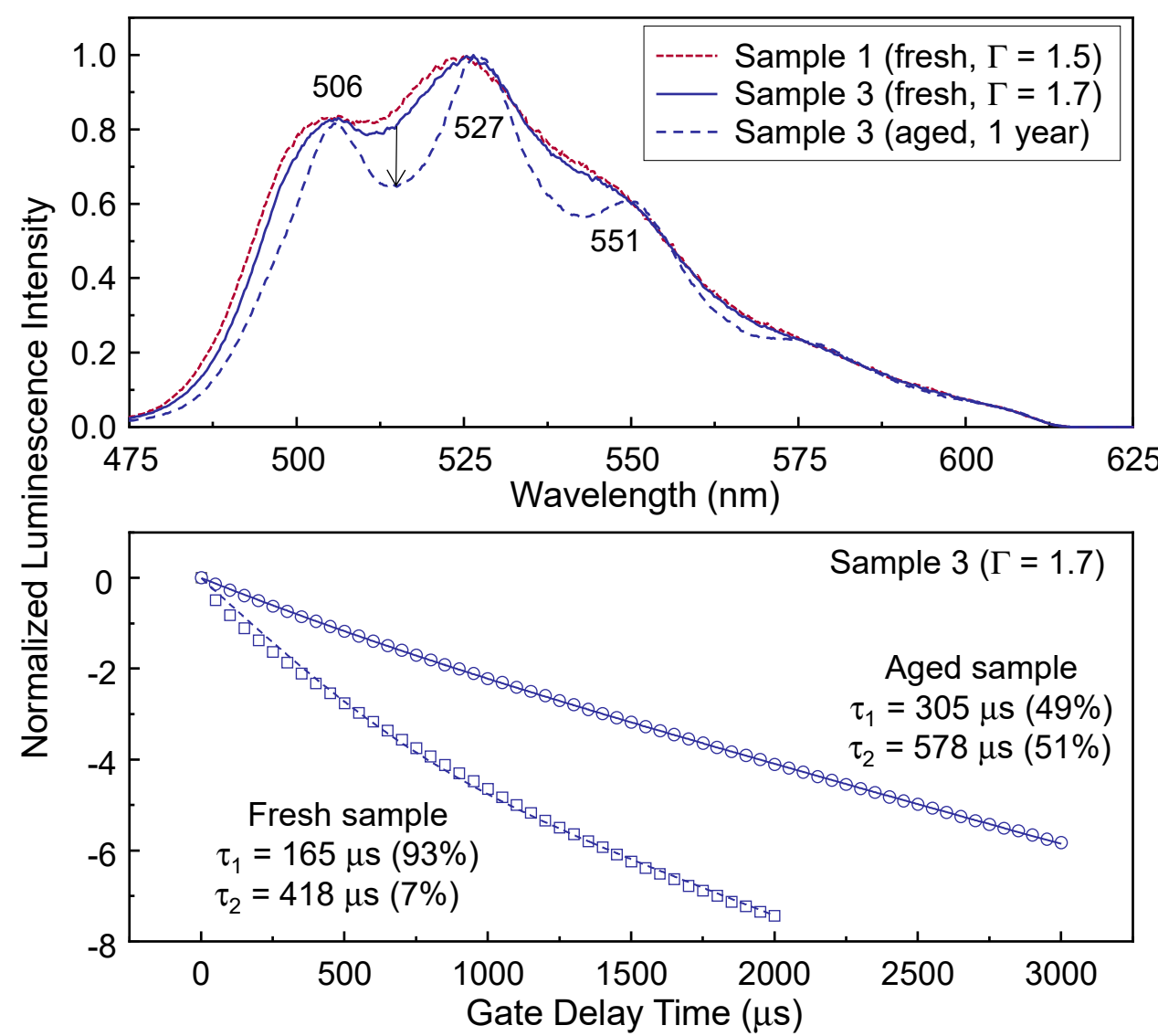

Figure 7. The luminescence spectra measured from the low and high SSA samples are compared in the upper panel. In the lower panel, the luminescence lifetimes of both species 1 and 2 increase with increasing ageing time. The $y$-axis is in a natural logarithmic scale.

\subsection{Excitation Wavelength- and Pulse Energy-Dependent Luminescence Properties}

In this subsection, the term 'laser-induced reaction' refers to changes in the luminescence intensity and/or spectral shape that occur during laser irradiation. Figure 8 depicts the laser-induced reaction effect generated by irradiating a laser beam with a pulse energy of $2.4 \mathrm{~mJ}$ at $\lambda_{\mathrm{ex}}=266 \mathrm{~nm}$ on the luminescence intensity of $\mathrm{U}(\mathrm{VI})$ surface species measured from the low SSA sample (sample No. 3, $[\mathrm{U}(\mathrm{VI})]=3.4 \mu \mathrm{M}$, and $m / v=1.0 \mathrm{~g} / \mathrm{L}$ ) at $\mathrm{pH} 7.5$. The luminescence spectra were measured at $t_{\mathrm{d}}=1 \mu \mathrm{s}$ as a function of the laser irradiation time. The normalized luminescence spectra maintain their shapes as the irradiation time increases, as shown in Figure 8a. The luminescence intensities in Figure 8b were obtained by integrating the signal from 475 to $600 \mathrm{~nm}$ in the luminescence spectrum and were normalized by the strongest value measured at an irradiation time of $0.2 \mathrm{~min}$. Figure $8 \mathrm{~b}$ reveals that the luminescence intensity decreases by approximately $38 \%$ after approximately 50 min of laser irradiation. This result can be understood in terms of the LITD of U(VI) surface species by the following processes: (1) when a portion of the laser pulse energy is absorbed into the surface, the localised surface heating induces thermal desorption of adsorbed species; and (2) the desorption of adsorbed U(VI) surface species results in an immediate decrease in the luminescence intensity [45-48]. 


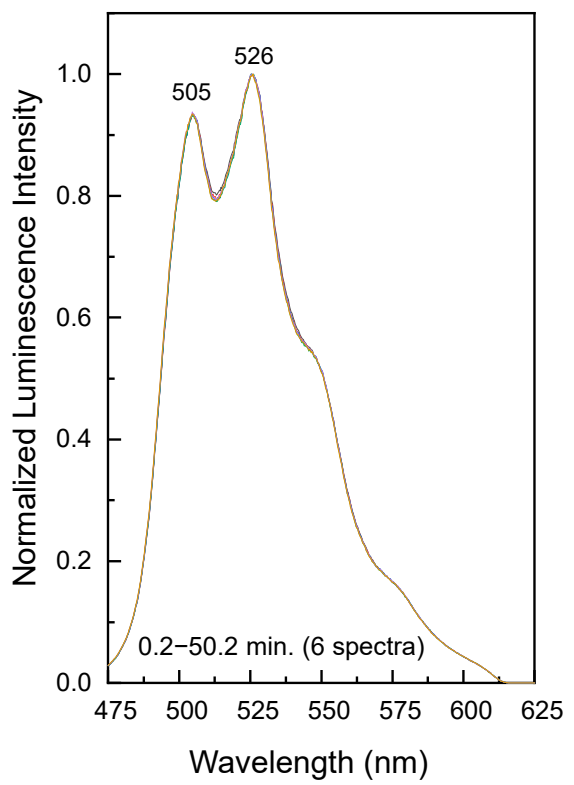

(a)

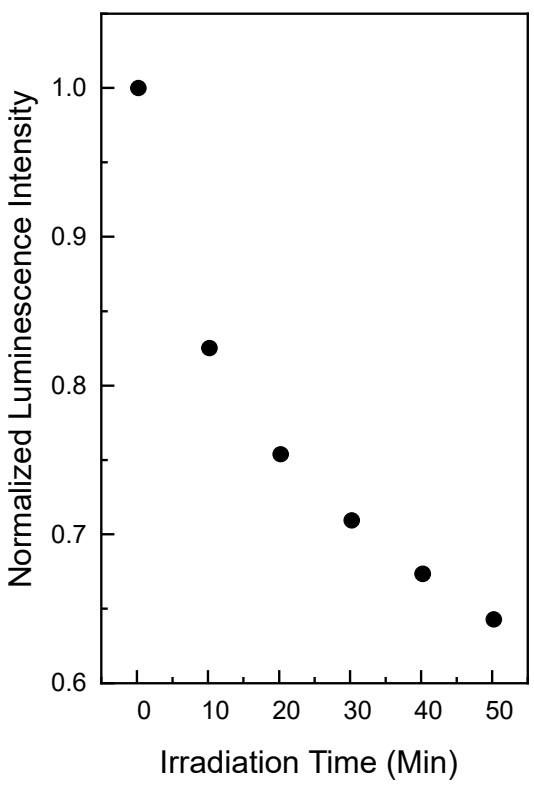

(b)

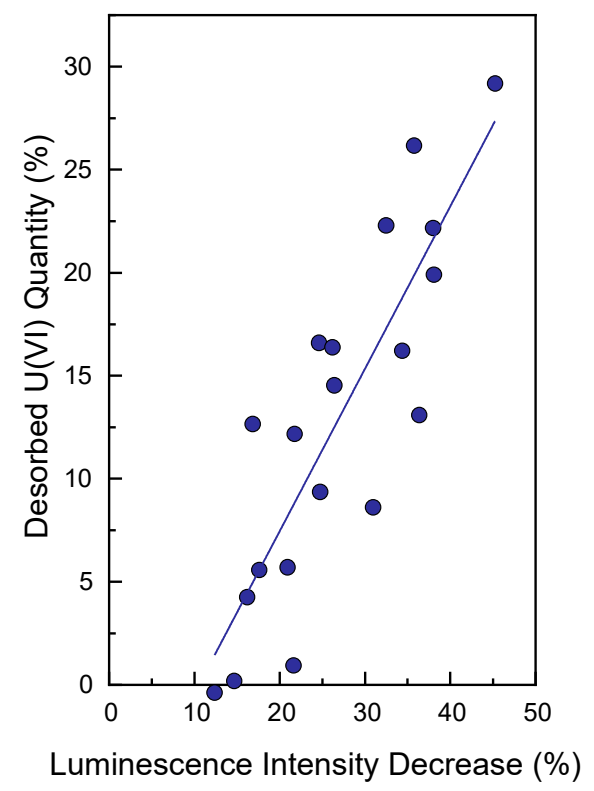

(c)

Figure 8. (a) Normalized luminescence spectra of U(VI) surface species for the low SSA sample (sample No. 3, [U(VI)] = 3.4 $\mu \mathrm{M}, m / v=1.0 \mathrm{~g} / \mathrm{L}, \mathrm{pH} 7.5$ ). (b) These data show the decrease in the luminescence intensity resulting from the laser-induced reaction at $\lambda_{\mathrm{ex}}=266 \mathrm{~nm}$. (c) Comparison of the desorbed U(VI) quantity with the decrease in the luminescence intensity for the low SSA samples.

The suitability of LITD as a cause of the laser-induced reaction was demonstrated by monitoring the desorbed $\mathrm{U}(\mathrm{VI})$ from the surface. Figure $8 \mathrm{c}$ represents the quantities of desorbed $\mathrm{U}(\mathrm{VI})$ in the filtrates obtained from the same $\mathrm{SiO}_{2}$ samples used in Figure $8 \mathrm{a}, \mathrm{b}$ at $\mathrm{pH}$ values of 6.2-7.2 irradiated under the same laser conditions. The X-axis in Figure 8c denotes the change in the luminescence intensity resulting from the laser-induced reaction, which was controlled by varying the irradiation time of the laser beam. Consequently, the luminescence intensities decreased by approximately $15-45 \%$. As soon as the laserinduced reaction was complete after laser irradiation, the samples were centrifuged and filtered for quantitative analysis of the desorbed U(VI). The Y-axis in Figure 8c denotes the quantities of desorbed U(VI) in the filtrates determined using ICP-AES. A large amount of U(VI) (up to nearly 30\% of the adsorbed U(VI)) was desorbed in the filtrates. The solid line in Figure $8 \mathrm{c}$ was obtained by fitting the data to a linear regression. The quantity of desorbed $\mathrm{U}(\mathrm{VI})$ is linearly dependent on the change in the luminescence intensity. This result provides direct evidence of LITD as the origin of the laser-induced reaction of the $\mathrm{U}(\mathrm{VI})$ surface species. Although the quantities of desorbed U(VI) correlate well with the changes in the luminescence intensities, the solid line with a slope of approximately 0.78 and an intercept of approximately -8.3 in Figure $8 \mathrm{c}$ indicates that the quantities of desorbed U(VI) are smaller than the changes in the luminescence intensities. The reason for this phenomenon is presumed to be that a small amount of U(VI) desorbed from the $\mathrm{SiO}_{2}$ surface is adsorbed on a quartz cell, and this was not used for quantitative analysis. Under the same measurement conditions, the luminescence intensity of the desorbed U(VI) species in the filtrate (approximately 20\% desorbed U(VI) sample) was about 680 times weaker than that of the adsorbed U(VI) species. Therefore, it does not significantly affect the luminescence spectral shapes of adsorbed U(VI) species, as shown in Figure 8a.

Because the absorbed laser energy is a prerequisite for localised surface heating, the dependence of the incident pulse energy on the laser-induced reaction extent was examined at $\lambda_{\mathrm{ex}}=266 \mathrm{~nm}$. Figure 9 shows the effect of the incident laser pulse energy on the luminescence intensity of the U(VI) surface species measured from the high SSA sample (sample No. 2) at $\mathrm{pH} 7.5,[\mathrm{U}(\mathrm{VI})]=0.34 \mu \mathrm{M}$, and $\mathrm{m} / v=1.0 \mathrm{~g} / \mathrm{L}$. The spectra were measured at $t_{\mathrm{d}}=1 \mu \mathrm{s}$ as a function of the laser irradiation time. The luminescence 
intensities shown in the graphs were obtained by integrating the signal from 475 to $600 \mathrm{~nm}$ in the luminescence spectrum. The luminescence intensity decreases more rapidly as the laser pulse energy increases. The luminescence intensities in the upper panel of Figure 9 are reduced by approximately $34 \%, 15 \%$, and $7 \%$ after approximately 50 min of irradiation by incident laser pulse energies of $2.4,1.2$, and $0.6 \mathrm{~mJ}$, respectively. There are no considerable changes in the luminescence intensities measured at the laser pulse energy of $0.1 \mathrm{~mJ}$. Under the same measurement conditions at the laser pulse energy of $0.1 \mathrm{~mJ}$, the luminescence intensity generated from pure $\mathrm{SiO}_{2}$ suspension without $\mathrm{U}(\mathrm{VI})$ was about $0.1-0.3 \%$ of the luminescence intensity measured in adsorbed U(VI) species. Accordingly, the offset value generated from the background signal in Figure 9 may be ignored. The lower panel of Figure 9 shows the replotted luminescence intensities of the upper panel of Figure 9 as a function of the incident laser pulse energy. Nonlinear growth of the luminescence intensities is observed with increasing laser pulse energy. The laser pulse energy-dependent nonlinear property becomes more severe as the irradiation time passes, as indicated by the dashed line in Figure 9.

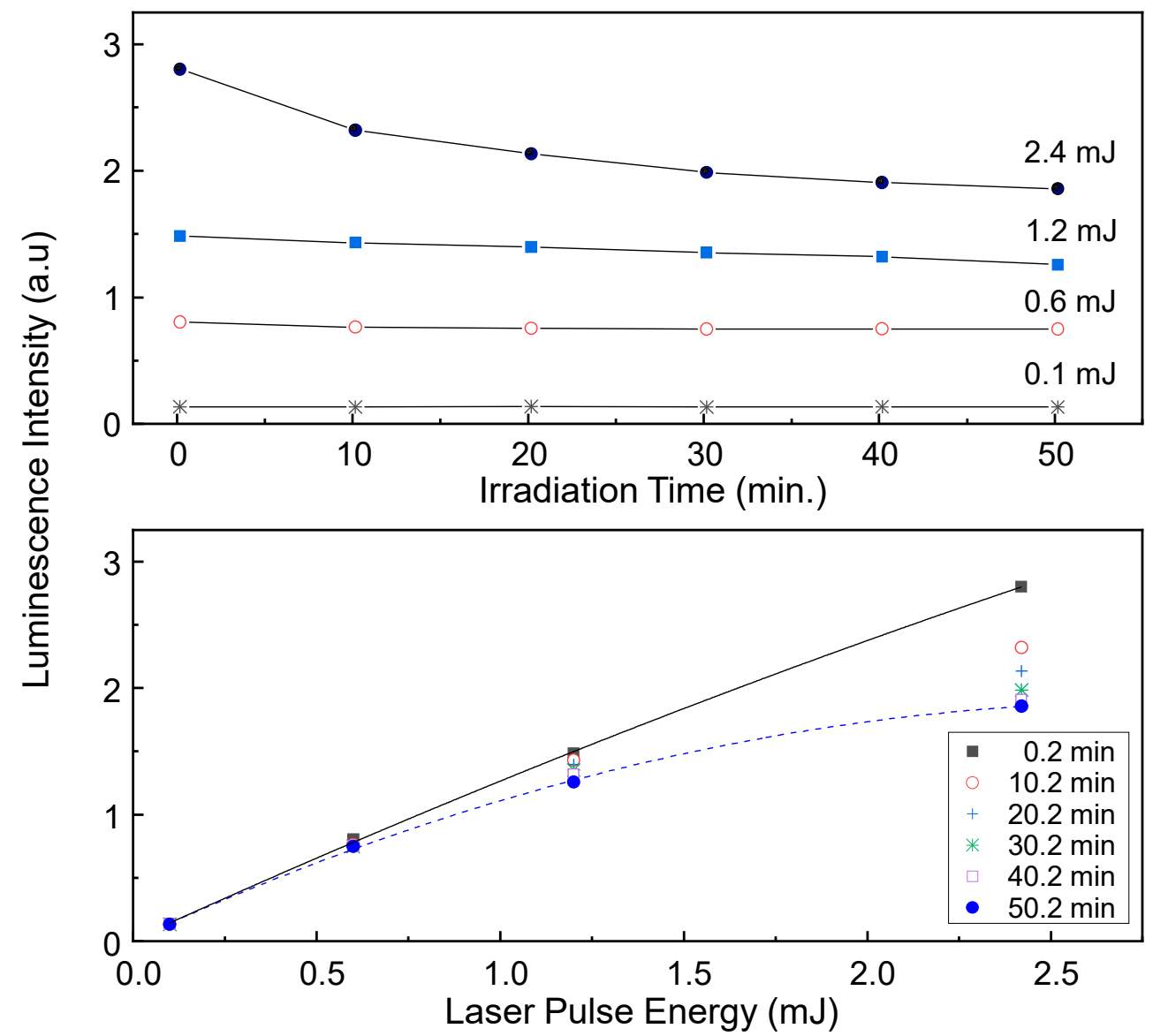

Figure 9. The upper panel shows the laser-induced reaction effect on the luminescence intensity at $\lambda_{\text {ex }}=266 \mathrm{~nm}$ for the high SSA sample (sample No. 2, $[\mathrm{U}(\mathrm{VI})]=0.34 \mu \mathrm{M}, m / v=1.0 \mathrm{~g} / \mathrm{L}, \mathrm{pH} 7.5$ ). The lower panel represents the luminescence intensities in the upper panel as a function of incident laser pulse energy. The solid and dashed lines show the results of fitting the data to the polynomial equation $(n=2)$.

The luminescence spectra of the U(VI) surface species used to derive the data presented in Figure 9 were normalized to the maximum intensity in Figure 10. The initial luminescence spectra, which were measured immediately at 0.2 min after laser irradiation, show almost identical shapes as the same $\mathrm{V} / \mathrm{P}$ intensity ratio under different laser pulse energies of 0.1-2.4 $\mathrm{mJ}$ in Figure 10. The spectral shapes of the U(VI) surface species measured at 
a laser pulse energy of $0.1 \mathrm{~mJ}$ in the left upper panel of Figure 10 do not change with increasing laser irradiation time. Because the measurements were performed for $\mathrm{SiO}_{2}$ samples, which were stored in a globe box for nearly four months, species 2 seems to exist predominantly due to the ageing effect as explained in the previous subsection. Interestingly, the normalized luminescence spectra measured under laser pulse energies of 0.6-2.4 mJ change shapes during laser irradiation. An increase in the laser pulse energy leads to a higher $\mathrm{V} / \mathrm{P}$ intensity ratio as the irradiation time passes, with the appearance of a shoulder at approximately $497 \mathrm{~nm}$, designated by an ellipse in the right lower panel of Figure 10. The fraction of the shoulder also increases with increasing laser pulse energy. The changes in the luminescence spectral shapes resulting from the laser-induced reaction under laser pulse energies of $0.6-2.4 \mathrm{~mJ}$ were ascribed to the appearance of the additional $\mathrm{U}(\mathrm{VI})$ species (called 'species 3 ') showing luminescence peaks located at shorter wavelengths. The change in the luminescence intensities of the $\mathrm{U}(\mathrm{VI})$ surface species displayed in the upper panel of Figure 9 is very similar to the results observed for the $\mathrm{U}(\mathrm{VI})-\mathrm{TiO}_{2}$ system, wherein the photoreduction of $\mathrm{U}(\mathrm{VI})$ dominates the laser-induced reaction [34,35]. The formation of non-luminescent $\mathrm{U}(\mathrm{IV})$ results in immediate decreases in the luminescence intensities of the $\mathrm{U}(\mathrm{VI})-\mathrm{TiO}_{2}$ system. However, the changes in the spectral shapes illustrated in Figure 10 constitute a newly observed phenomenon that has not been reported for the $\mathrm{U}(\mathrm{VI})-\mathrm{TiO}_{2}$ system in previous studies [34,35]. This observation indicates that the photoreduction of $\mathrm{U}(\mathrm{VI})$ to $\mathrm{U}(\mathrm{IV})$ is not the major mechanism of the laser-induced reaction observed for this $\mathrm{U}(\mathrm{VI})-\mathrm{SiO}_{2}$ system.
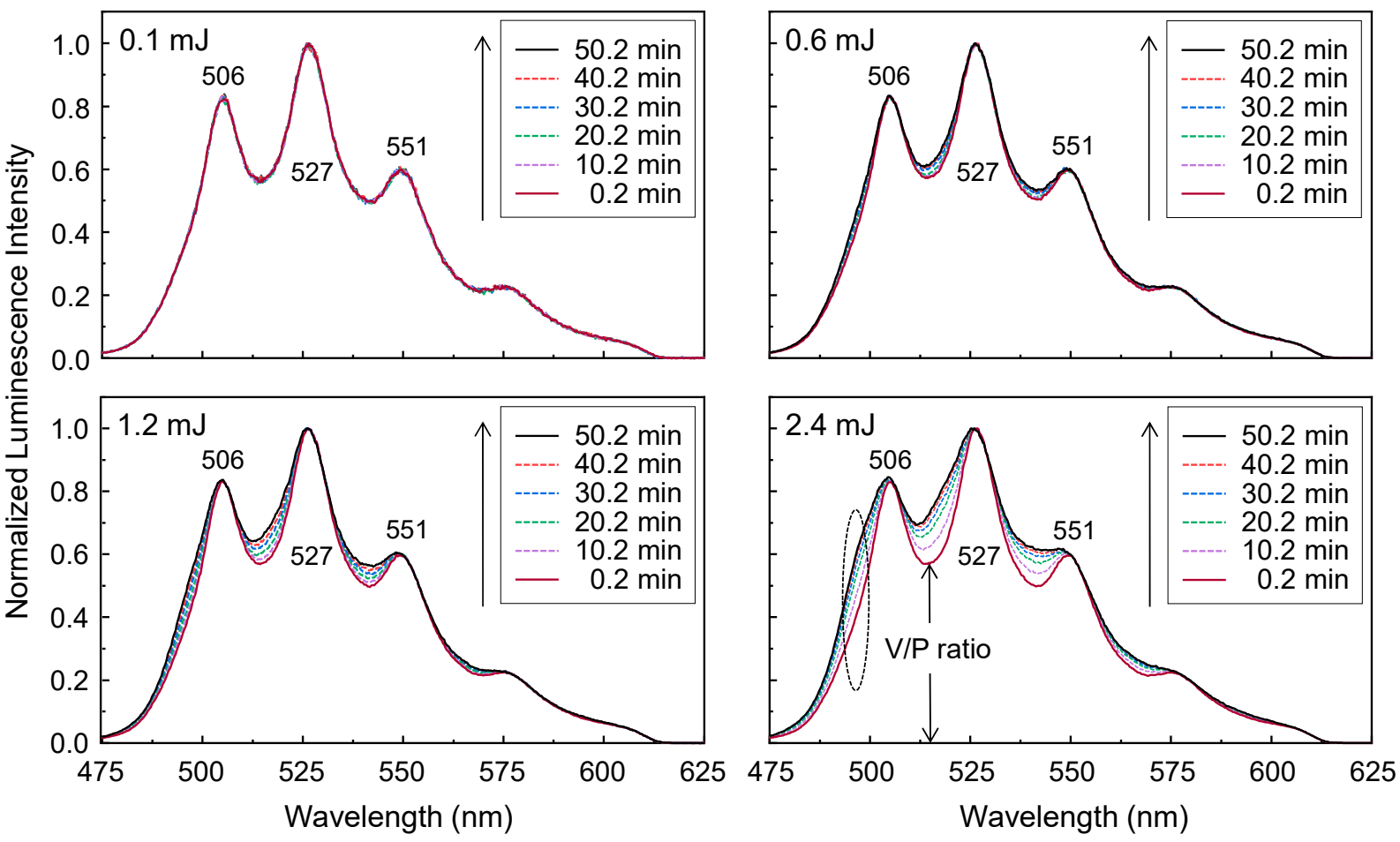

Figure 10. Normalized luminescence spectra of the U(VI) surface species used to derive the data presented in Figure 9. An increase in the laser pulse energy leads to a higher V/P intensity ratio with the appearance of a shoulder at approximately $497 \mathrm{~nm}$, designated as an ellipse in the right lower panel.

The upper panel of Figure 11 shows the luminescence spectra of the same $\mathrm{SiO}_{2}$ sample used to obtain Figures 9 and 10, measured at $\lambda_{\mathrm{ex}}=355 \mathrm{~nm}$. The luminescence intensities of these spectra were not normalized. There are no significant changes in either the luminescence intensities or spectral shapes during the laser irradiation even at a laser pulse energy of $2.4 \mathrm{~mJ}$. The lower panel of Figure 11 presents the luminescence 
intensities as a function of the incident laser pulse energy. Unlike the intensities in Figure 9 measured at $\lambda_{\mathrm{ex}}=266 \mathrm{~nm}$, the luminescence intensities at $\lambda_{\mathrm{ex}}=355 \mathrm{~nm}$ increase linearly with increasing laser pulse energy. The solid line represents the results of fitting the data to a linear equation.

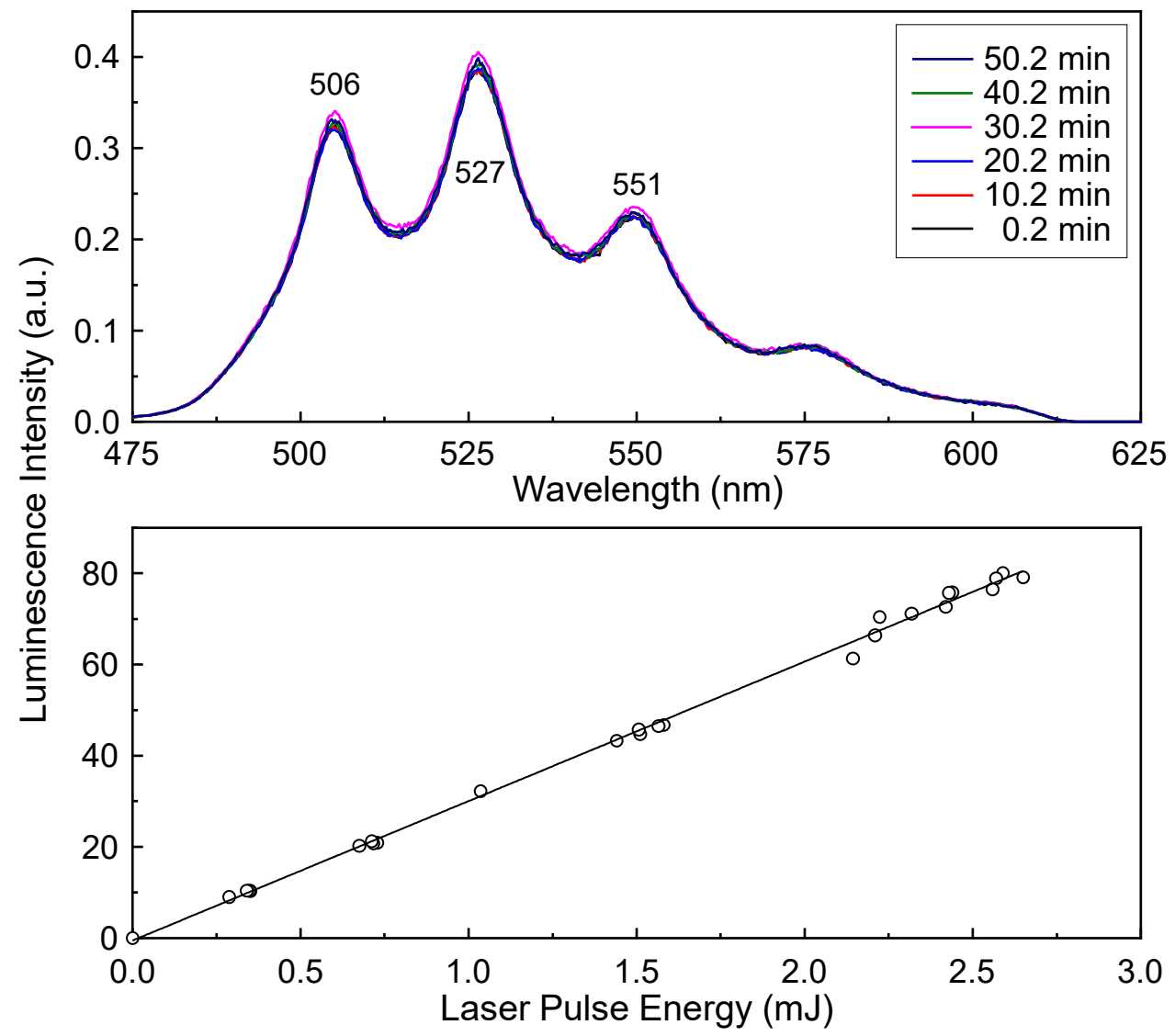

Figure 11. The upper panel shows lluminescence spectra for the same $\mathrm{SiO}_{2}$ sample used to obtain Figures 9 and 10, but with $\lambda_{\mathrm{ex}}=355 \mathrm{~nm}$ (laser pulse energy of $2.4 \mathrm{~mJ}$ ). The lower panel shows the luminescence intensity plotted as a function of laser pulse energy at $355 \mathrm{~nm}$.

A comparison of the results in Figure 11 with those in Figures 9 and 10 suggests that the laser-induced reaction does not occur at $\lambda_{\mathrm{ex}}=355 \mathrm{~nm}$. The luminescence spectra of the same $\mathrm{SiO}_{2}$ sample shown in Figures 9 and 10 measured at $\lambda_{\mathrm{ex}}=422 \mathrm{~nm}$, corresponding to the absorption band of the surface U(VI) species [31], suggest that the laser-induced reaction also does not occur at $\lambda_{\mathrm{ex}}=422 \mathrm{~nm}$ with a laser pulse energy of $2.4 \mathrm{~mJ}$, as shown in Figure S12a. In a previous study, the excitation spectrum measured at $\lambda_{\mathrm{ex}}=266 \mathrm{~nm}$ showed a much higher intensity than those measured at $\lambda_{\mathrm{ex}}=355$ and $422 \mathrm{~nm}$ [31]. This finding means that a much larger laser energy is absorbed by the surface at $266 \mathrm{~nm}$ than at other wavelengths. Consequently, the luminescence intensity at $\lambda_{\mathrm{ex}}=266 \mathrm{~nm}$ is approximately 40 times stronger than the intensities measured at $\lambda_{\mathrm{ex}}=355$ and $422 \mathrm{~nm}$ at the same laser pulse energy of $2.4 \mathrm{~mJ}$, as shown in Figure S12b.

PARAFAC analysis was applied for decomposition of the luminescence spectra displayed in Figure 10, Figure 11 and Figure S12. For those in the process of the laser-induced reaction, the decomposition with two spectral components (species 2 and 3) converges well with high core-consistency values (99.7-100\%). As representative PARAFAC analysis results, the results of decomposition from the spectra in the right lower panel of Figure 10 are presented in Figure 12. When the laser-induced reaction does not occur, such as in the spectra in Figure 10 (left upper panel), Figure 11, and Figure S12, a unique component corresponding to species 2 exists. The average luminescence lifetimes at three different wavelengths were determined to be $\tau_{2}=649 \pm 28 \mu \mathrm{s}$, as listed in Table 3 . This value 
corresponds to the value determined in Figure $6\left(\tau_{2}=653 \pm 12 \mu \mathrm{s}\right)$. The luminescence spectral shape of species 3 in Figure 12 and its lifetime in Table 3 resemble those of species 1 $\left(\tau_{1}=296 \pm 17 \mu \mathrm{s}\right)$, as explained in the previous subsection.
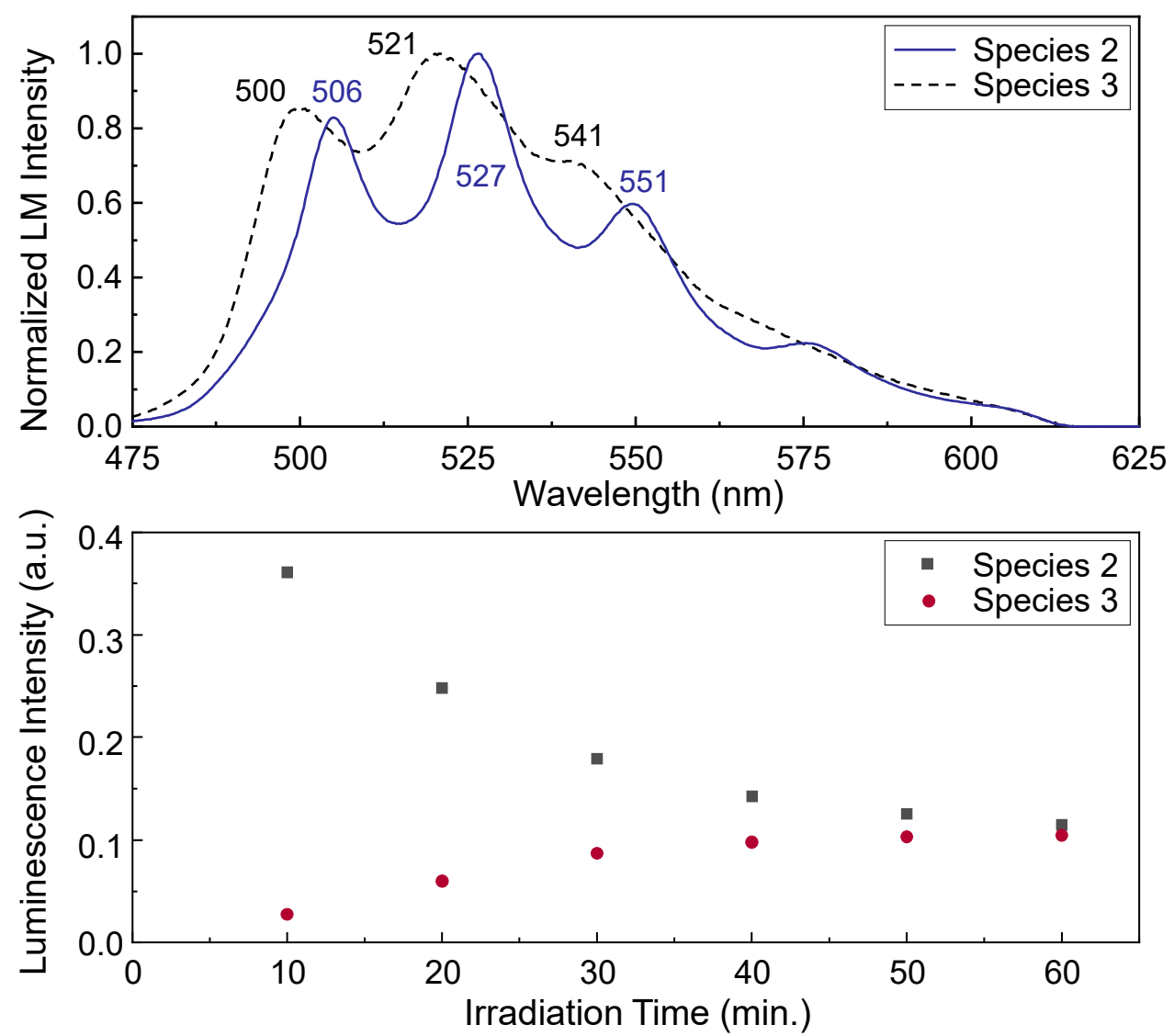

Figure 12. The upper panel shows PARAFAC analysis results for decomposition of the luminescence (LM) spectra displayed in the right lower panel of Figure 10. In the lower panel, the luminescence intensities of species 3 gradually increase as the irradiation time passes with decreasing luminescence intensity of species 2 .

Table 3. Luminescence lifetimes of $\mathrm{U}(\mathrm{VI})$ in $\mathrm{SiO}_{2}$, shown in Figure 10, Figure 11 and Figure S12, determined using PARAFAC analysis.

\begin{tabular}{ccc}
\hline Laser Pulse Energy (Excitation Wavelength) & Species 2 $(\boldsymbol{\mu s})$ & Species 3 $(\boldsymbol{\mu s})$ \\
\hline $2.4 \mathrm{~mJ}(355 \mathrm{~nm})$ & & - \\
$2.4 \mathrm{~mJ}(422 \mathrm{~nm})$ & $649 \pm 28$ & \\
$0.1 \mathrm{~mJ}(266 \mathrm{~nm})$ & & 313 \\
\hline $0.6 \mathrm{~mJ}(266 \mathrm{~nm})$ & 621 & 292 \\
$1.2 \mathrm{~mJ}(266 \mathrm{~nm})$ & 610 & 287 \\
\hline $2.4 \mathrm{~mJ}(266 \mathrm{~nm})$ & 575 & \\
\hline
\end{tabular}

Under the conditions wherein the laser-induced reaction occurs at $\lambda_{\mathrm{ex}}=266 \mathrm{~nm}$, the lifetimes of species 2 listed in Table 3 decrease gradually to approximately $575 \mu$ s with increasing laser pulse energy. Considering the nonlinear increase in the luminescence intensity as a function of the incident laser pulse energy observed in Figure 9, the transfer of a portion of the absorbed laser energy into the thermal heating of the surface presumably promotes the nonradiative decay process. Thus, the excited-state lifetimes determined with high laser energy absorption at $\lambda_{\mathrm{ex}}=266 \mathrm{~nm}$ become shorter owing to the increases in the relevant processes (radiative and nonradiative) that relax the electronic excited states back to the ground state. The lower panel of Figure 12 shows the change in the 
species distribution determined using PARAFAC analysis. The luminescence intensities of species 3 gradually increase with increasing irradiation time, whereas those of species 2 decrease.

As soon as the laser-induced reaction was complete after $1 \mathrm{~h}$ of laser irradiation at $\lambda_{\mathrm{ex}}=266 \mathrm{~nm}$, sample No. $2([\mathrm{U}(\mathrm{VI})]=0.34 \mu \mathrm{M}, m / v=1.0 \mathrm{~g} / \mathrm{L}$, and $\mathrm{pH} 7.5)$ was irradiated at $\lambda_{\mathrm{ex}}=422 \mathrm{~nm}$ with a laser pulse energy of $1.7 \mathrm{~mJ}$ to monitor the evolution of the luminescence spectrum with time. The luminescence spectral shapes measured at $t_{\mathrm{d}}=1 \mu$ s recover over a long period of time, as shown in the upper panel of Figure 13. The luminescence intensity of species 3 gradually decreases with time; thus, the $V / P$ intensity ratio and the fraction of the shoulder decrease, as indicated by the arrow in Figure 13. These observations demonstrate that the newly appeared species, species 3, resulting from the laser-induced reaction for the high SSA sample, continuously disappears with time. Meanwhile, the luminescence intensity of species 2 increases with time. The lower panel of Figure 13 shows the change in the species distribution as a function of the signal recovery time. PARAFAC analysis was applied for decomposition of the luminescence spectra displayed in the upper panel of Figure 13. The decomposition with two spectral components converges well with a high core-consistency value of $99.8 \%$. The origin of the X-coordinate in the lower panel denotes the time at which the UV laser irradiation ends. The luminescence intensities of species 2 are recovered fast over the first two days with decreasing luminescence intensity of species 3 .
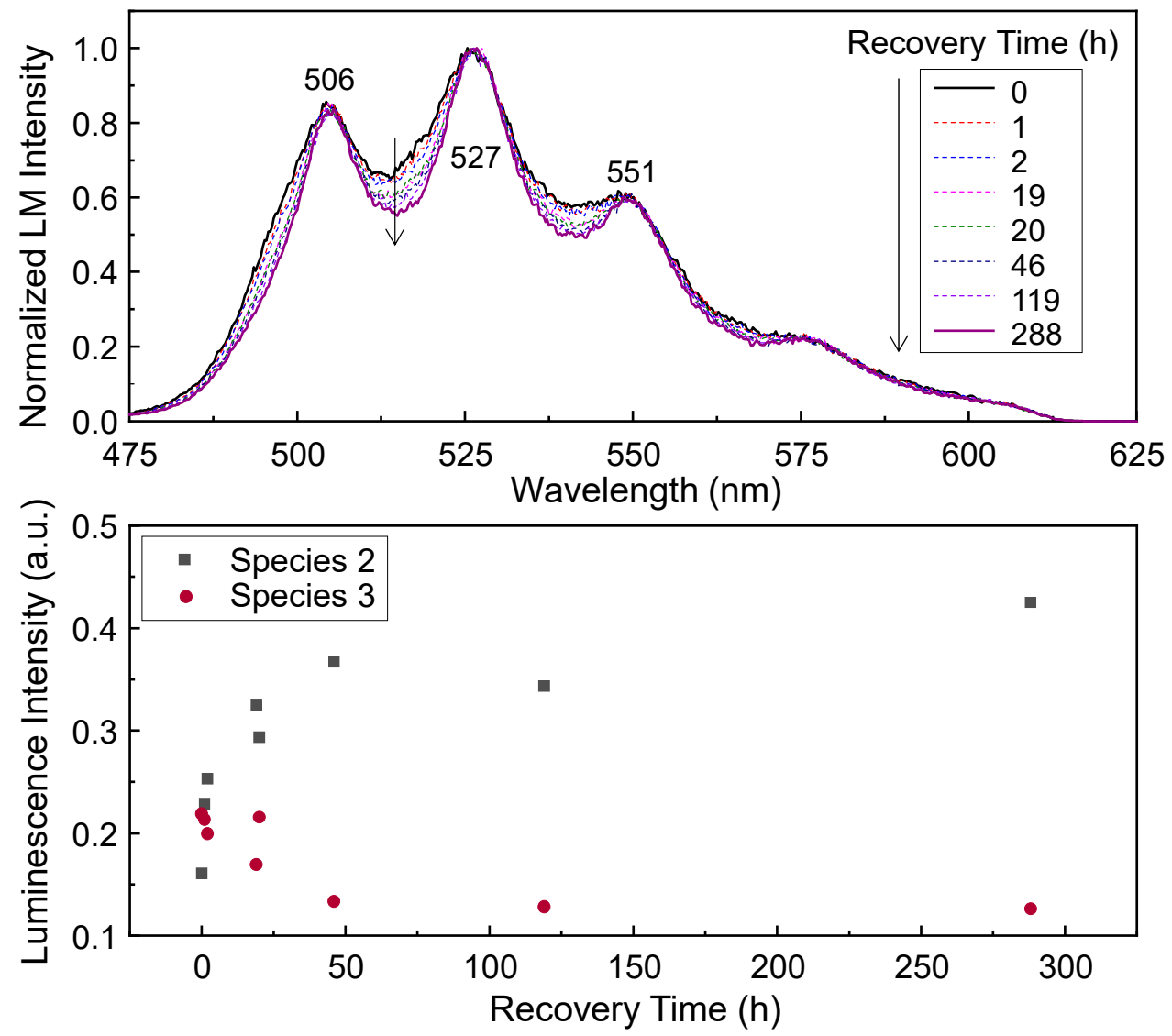

Figure 13. As soon as the laser irradiation at $266 \mathrm{~nm}$ was complete (high SSA sample No. 2, $[\mathrm{U}(\mathrm{VI})]=0.34 \mu \mathrm{M}, m / v=1.0 \mathrm{~g} / \mathrm{L}$, and $\mathrm{pH} 7.5)$, the luminescence spectra were measured at $422 \mathrm{~nm}$ to monitor the evolution of the luminescence spectrum. In the upper panel, the spectral shapes measured at $t_{\mathrm{d}}=1 \mu \mathrm{s}$ are recovered over a long period of time. In the lower panel, PARAFAC analysis shows that the luminescence intensities of species 2 gradually increase as the recovery time passes with decreasing luminescence intensity of species 3 . 
As described in the previous subsection, the increase in species 2 at the expense of species 3 with time suggests that species 3 is unstable. Thus, a reasonable hypothesis is that species 3, which appears during the laser-induced reaction, is analogous to species 1 under near-neutral $\mathrm{pH}$ conditions. The appearance and disappearance of species 3 shown in Figures 12 and 13, respectively, were easily observed in $\mathrm{SiO}_{2}$ samples with high SSA, but difficult to observe in samples with low SSA. If these phenomena are due to a result of a change in the equilibrium of $\mathrm{U}(\mathrm{VI})$-hydroxo species by the thermal heating of the surface, these phenomena should be observed even in $\mathrm{SiO}_{2}$ samples with low SSA. From the photoreduction perspective, $\mathrm{U}$ reoxidation cannot contribute to the luminescence signal recovery because of the formation of a non-luminescent end product, such as an oxide with a structure intermediate between $\mathrm{UO}_{2}$ and $\mathrm{UO}_{3}$, possibly $\mathrm{U}_{3} \mathrm{O}_{8}[34,49]$.

Figure 14 shows the luminescence properties measured for the dissolved $\mathrm{U}(\mathrm{VI})$ species by laser irradiation. As soon as the laser-induced reaction was complete with a net decrease of approximately $28 \%$ in the luminescence intensity after $1 \mathrm{~h}$ of laser irradiation at $\lambda_{\mathrm{ex}}=266 \mathrm{~nm}$ with a laser pulse energy of $2.4 \mathrm{~mJ}$, the suspension (high SSA sample No. 2 at $\mathrm{pH} 7.5,[\mathrm{U}(\mathrm{VI})]=3.4 \mu \mathrm{M}$, and $m / v=1.0 \mathrm{~g} / \mathrm{L})$ was centrifuged and filtered for quantitative analysis of the dissolved $\mathrm{U}(\mathrm{VI})$. The luminescence spectrum of the dissolved $\mathrm{U}(\mathrm{VI})$ species in the filtrate illustrated as a solid line in the upper panel of Figure 14 shows peak positions at approximately 500,520,544, and $572 \mathrm{~nm}$. The dotted line represents the background luminescence spectrum of the species existing in the filtrate of the same batch of the $\mathrm{SiO}_{2}$ sample, but without laser irradiation. The observation of much stronger luminescence after $1 \mathrm{~h}$ of laser irradiation than that of the background spectrum indicates that the increase in the dissolved $\mathrm{U}(\mathrm{VI})$ species results from the desorption of $\mathrm{U}(\mathrm{VI})$ from the $\mathrm{SiO}_{2}$ surface.
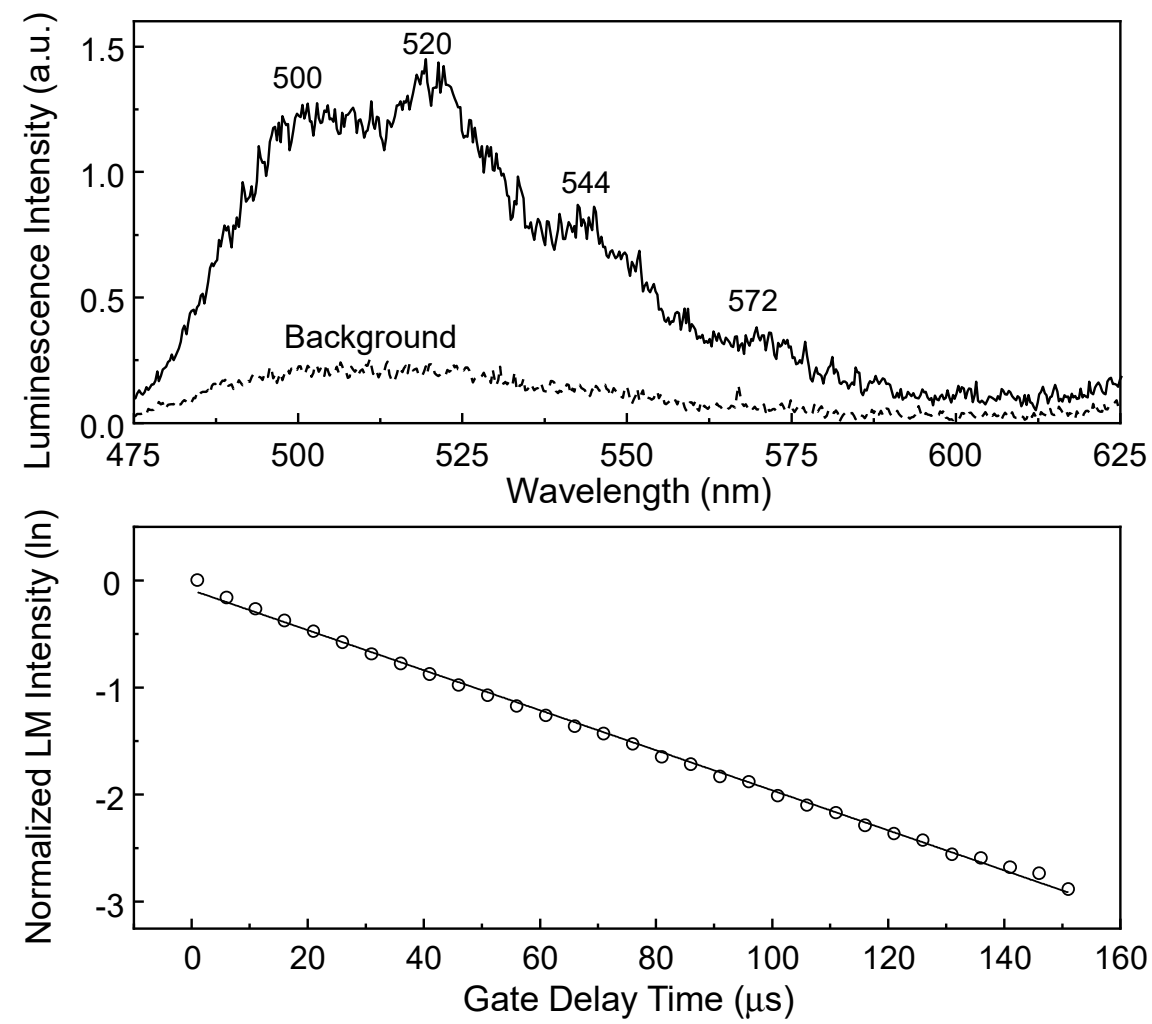

Figure 14. Comparison of the luminescence spectrum of the desorbed U(VI) species in the filtrate with the background luminescence spectrum of the species existing in the filtrate obtained from the same high SSA sample (sample No. 2, $[\mathrm{U}(\mathrm{VI})]=3.4 \mu \mathrm{M}, m / v=1.0 \mathrm{~g} / \mathrm{L}$, and $\mathrm{pH} 7.5$ ) before laser irradiation. The lower panel shows the luminescence intensity on the natural logarithmic scale corresponding to gate delay times of 1-151 $\mu \mathrm{s}$. The slope of the solid line was used to determine the luminescence lifetime of $52 \pm 17 \mu$ s. 
The lower panel of Figure 14 shows the luminescence lifetime measured from the dissolved U(VI) species in the upper panel of Figure 14. The luminescence intensities depicted as symbols were obtained from a series of luminescence spectra measured using the kinetic mode of the ICCD with $t_{\mathrm{w}}=10 \mu \mathrm{s}$ and a $t_{\mathrm{d}}$ between $1 \mu \mathrm{s}$ and $151 \mu$ s (step size of $5 \mu \mathrm{s})$. The symbols and solid lines in the lower panel denote the normalized luminescence intensities on the natural logarithmic scale and the results of fitting the data to a linear regression, respectively. For several filtrates, the luminescence lifetime of the dissolved $\mathrm{U}(\mathrm{VI})$ species was determined to be $\tau=52 \pm 17 \mu \mathrm{s}$. The peak wavelengths and luminescence lifetime of the $\mathrm{U}(\mathrm{VI})$ species in Figure 14 are comparable to previously reported values (peak wavelengths of 500,521,544, and $570 \mathrm{~nm}$ and a lifetime of $19 \pm 4 \mu \mathrm{s}$ ) at $\mathrm{pH} 3.9$ for the complex in the $\mathrm{U}(\mathrm{VI})$-silicate system, such as the $\mathrm{UO}_{2} \mathrm{OSi}(\mathrm{OH})_{3}{ }^{+}$species [16].

In Figure 14, the quantity of desorbed U(VI) in the filtrate determined using ICP-MS is $0.1 \mu \mathrm{M}$, which corresponds to approximately $3 \%$ of the adsorbed quantity of $3.4 \mu \mathrm{M}$. The quantity of background U(VI) species before laser irradiation was smaller than the detection limit of the analytical instrument. The amount of desorbed U(VI) in the filtrate is quite small compared to the desorbed quantities of approximately $30 \%$ for the low SSA samples, as shown in Figure 8c. This phenomenon is attributed to the readsorption of the dissolved U(VI) species, which is responsible for the newly appearing species, species 3 , as illustrated in the right lower panel of Figure 10. Considering that the lower adsorption sites of the low SSA samples prevent the desorbed U(VI) from readsorption during the laser irradiation, a large quantity of desorbed U(VI) is expected in filtrates obtained from the low SSA samples. A comparison of the spectra in Figure 8 with those in the right lower panel of Figure 10 reveals that there are no additional U(VI) species in the low SSA sample.

\section{Conclusions}

The comprehensive study presented in this manuscript clarifies the experimental factors that affect the luminescence properties of the $\mathrm{U}(\mathrm{VI})-\mathrm{SiO}_{2}$ system, resulting in inconsistent luminescence lifetimes and spectral shapes in previous studies. The key findings described in '3.1. Surface Coverage-Dependent Luminescence Properties' subsection show that the luminescence properties of the $U(V I)$ surface species depend on $\Gamma$. For the three considered $\mathrm{SiO}_{2}$ samples, the luminescence lifetimes increased as $\Gamma$ decreased. Simultaneously, the $\mathrm{V} / \mathrm{P}$ intensity ratios of the luminescence spectral shapes decreased as $\Gamma$ decreased. The longest luminescence lifetime of U(VI)-hydroxo surface species, denoted as species 2 in this report, was approximately $650 \mu$ s in the $\Gamma$ region below $0.01 \mu$ mol $\mathrm{U} / \mathrm{m}^{2}$. The U(VI)-hydroxo surface species are likely highly coordinated by $\mathrm{SiO}_{2}$ in the low $\Gamma$ region, where a relatively large number of adjacent surface sites are involved in surface complexation. The possible displacement of coordinated water molecules in the equatorial plane of U(VI) results in a longer luminescence lifetime. The importance of the adjacent surface sites was further verified by observing the $\mathrm{pH}$-dependent luminescence lifetimes. The ageing time-dependent luminescence properties revealed the stability of the U(VI)-hydroxo surface species. Further work should focus on the chemical speciation of unstable U(VI) surface species, denoted as species 1 in this study, in the near-neutral $\mathrm{pH}$ range. In '3.2. Excitation Wavelength- and Pulse Energy-Dependent Luminescence Properties' subsection, the laser-induced reaction in the $\mathrm{U}(\mathrm{VI})-\mathrm{SiO}_{2}$ system by LITD was observed. For both the low and high $\mathrm{SSA} \mathrm{SiO}_{2}$ samples, the higher the UV laser pulse energy, the greater the decrease in luminescence intensity. This effect can lead to misinterpretation of the luminescence characteristics of U(VI) surface species. For example, when LITD occurs during luminescence lifetime measurement, the lifetime is determined inaccurately because of the excessive decrease in the luminescence intensity caused by the U(VI) desorbed from the surface. It was also confirmed that irradiation of the $\mathrm{SiO}_{2}$ surface by a UV laser beam at a high pulse energy changed both the luminescence lifetime and spectral shape. The results obtained in the present study provide detailed information for the reliable measurements of the luminescence characteristics of U(VI) surface species in oxide and mineral systems. 
Supplementary Materials: The following are available online at https:/ /www.mdpi.com/article/10 $.3390 / \min 12020230 /$ s1, Table S1: Previously reported U(VI) surface species, thermodynamic surface complexation constants, and luminescence lifetimes. All measurements were conducted at room temperature. Table S2: Luminescence lifetimes and relative quantities of species 1 and 2 measured from the high SSA $\mathrm{SiO}_{2}$ (sample No. 2, pH 7.5). Table S3: Luminescence lifetimes and relative quantities of species 1 and 2 measured from the low SSA SiO 2 (sample No. 3, pH 7.5). Figure S1: (a) Adsorption edge of $\mathrm{U}(\mathrm{VI}) / \mathrm{SiO}_{2}$ system (b) The Schematic diagram of the experimental setup for TRLFS. Figure S2: Normalized luminescence spectra of U(VI) adsorbed onto high $\mathrm{SSA} \mathrm{SiO}_{2}$ (sample No. 2) under various $\mathrm{pH}$ conditions. Figure S3: Normalized luminescence spectra derived from the data in Figure 2. Figure S4: The luminescence lifetime of the species 2 can be determined by fitting the luminescence intensities measured at various gate delay times in the range of 2001-3001 $\mu$ s. Figure S5: PARAFAC analysis obtained from the six spectra displayed in Figure 2. Figure S6: Ageing time effect on the luminescence properties. Figure S7: $\Gamma$-dependent luminescence spectral shapes measured from the high $\mathrm{SSA} \mathrm{SiO}_{2}$ (sample No. 2, $\mathrm{pH} 7.5$ ) under various $[\mathrm{U}(\mathrm{VI})] /(\mathrm{m} / \mathrm{v})$ ratios. Figure S8: Luminescence lifetimes of U(VI) surface species measured from the samples used to obtain Figure S7. Figure S9: (a) Luminescence lifetimes in Table S2 as a function of $\Gamma$. (b) The relative contents of species 1 and 2. Figure S10: $\Gamma$-dependent luminescence properties measured from the low $\mathrm{SSA} \mathrm{SiO}_{2}(\mathrm{sample}$ No. 3, pH 7.5) under various $[\mathrm{U}(\mathrm{VI})] /(\mathrm{m} / \mathrm{v})$ ratios. Figure S11: Luminescence lifetimes in Table S3 as a function of $\Gamma$. (b) The relative contents of species 1 and 2. Figure S12: (a) The luminescence intensities measured at $\lambda_{\mathrm{ex}}=422 \mathrm{~nm}$ for the same $\mathrm{SiO}_{2}$ sample used in Figure. 9. (b) Comparison of luminescence intensity measured at $\lambda_{\mathrm{ex}}=266 \mathrm{~nm}$ with the intensities measured at $\lambda_{\mathrm{ex}}=355$ and $422 \mathrm{~nm}$.

Author Contributions: Formal analysis, T.-H.K., H.-K.K. and H.-R.C.; investigation, E.C.J., Y.J.; writing, E.C.J.; review and editing, J.-I.Y., H.-K.K., M.H.B. and W.C. All authors have read and agreed to the published version of the manuscript.

Funding: This research was funded by the Nuclear Research and Development Program of the National Research Foundation of Korea, grant number 2017M2A8A5014719, and by the Institute for Korea Spent Nuclear Fuel and the National Research Foundation of Korea, grant number 2021M2E1A1085202.

Conflicts of Interest: The authors declare no conflict of interest.

\section{References}

1. McKinley, J.P.; Zachara, J.M.; Smith, S.C.; Turner, G.D. The influence of uranyl hydrolysis and multiple site-binding reactions on adsorption of U(VI) to montmorillonite. Clays Clay Miner. 1995, 43, 586-598. [CrossRef]

2. Batuk, D.N.; Shiryaev, A.A.; Kalmykov, S.N.; Batuk, O.N.; Romanchuk, A.Y.; Shirshin, E.A.; Zubavichus, Y.V. Sorption and speciation of uranium on silica colloids. In Actinide Nanoparticle Research; Kalmykov, S.N., Denecke, M.A., Eds.; Springer: Berlin/Heidelberg, Germany, 2011; pp. 315-332.

3. Massey, M.S.; Lezama-Pacheco, J.S.; Nelson, J.M.; Fendorf, S.; Maher, K. Uranium incorporation into amorphous silica. Environ. Sci. Technol. 2014, 48, 8636-8644. [CrossRef] [PubMed]

4. Comarmond, M.J.; Steudtner, R.; Stockmann, M.; Heim, K.; Müller, K.; Brendler, V.; Payne, T.E.; Foerstendorf, H. The sorption process of $\mathrm{U}(\mathrm{VI})$ onto $\mathrm{SiO}_{2}$ in the presence of phosphate: From binary surface species to precipitation. Environ. Sci. Technol. 2016, 50, 11610-11618. [CrossRef] [PubMed]

5. Tan, X.; Fang, M.; Wang, X. Sorption speciation of lanthanides/actinides on minerals by TRLFS, EXAFS and DFT Studies: A review. Molecules 2010, 15, 8431-8468. [CrossRef] [PubMed]

6. Geckeis, H.; Lützenkirchen, J.; Polly, R.; Rabung, T.; Schmidt, M. Mineral-water interface reactions of actinides. Chem. Rev. 2013, 113, 1016-1062. [CrossRef]

7. Maher, K.; Bargar, J.R.; Brown, G.E., Jr. Environmental speciation of actinides. Inorg. Chem. 2013, 52, 3510-3532. [CrossRef]

8. Dent, A.J.; Ramsay, J.D.F.; Swanton, S.W. An EXAFS study of uranyl ion in solution and sorbed onto silica and montmorillonite clay colloids. J. Colloid Interface Sci. 1992, 150, 45-60. [CrossRef]

9. Reich, T.; Moll, H.; Denecke, M.A.; Geipel, G.; Bernhard, G.; Nitsche, H.; Allen, P.G.; Bucher, J.J.; Kaltsoyannis, N.; Edelstein, N.M.; et al. Characterization of hydrous uranyl silicate by EXAFS. Radiochim. Acta 1996, 74, 219-223. [CrossRef]

10. Reich, T.; Moll, H.; Arnold, T.; Denecke, M.A.; Hennig, C.; Geipel, G.; Bernhard, G.; Nitsche, H.; Allen, P.G.; Bucher, J.J.; et al. An EXAFS study of uranium(VI) sorption onto silica gel and ferrihydrite. J. Electron Spectrosc. Relat. Phenom. 1998, 96, 237-243. [CrossRef]

11. Sylwester, E.R.; Hudson, E.A.; Allen, P.G. The structure of uranium(VI) sorption complexes on silica, alumina, and montmorillonite. Geochim. Cosmochim. Acta 2000, 64, 2431-2438. [CrossRef] 
12. Walter, M.; Arnold, T.; Geipel, G.; Scheinost, A.; Bernhard, G. An EXAFS and TRLFS investigation on uranium(VI) sorption to pristine and leached albite surfaces. J. Colloid Interface Sci. 2005, 282, 293-305. [CrossRef]

13. Kowal-Fouchard, A.; Drot, R.; Simoni, E.; Ehrhardt, J.J. Use of spectroscopic techniques for uranium(VI)/montmorillonite interaction modelling. Environ. Sci. Technol. 2004, 38, 1399-1407. [CrossRef]

14. Drot, R.; Roques, J.; Simoni, É. Molecular approach of the uranyl/mineral interfacial phenomena. C. R. Chim. 2007, 10, 1078-1091. [CrossRef]

15. Wheeler, J.; Thomas, J.K. Photochemistry of the uranyl ion in colloidal silica solution. J. Phys. Chem. 1984, 88, 750-754. [CrossRef]

16. Moll, H.; Geipel, G.; Brendler, V.; Bernhard, G.; Nitsche, H. Interaction of uranium(VI) with silicic acid in aqueous solutions studied by time-resolved laser-induced fluorescence spectroscopy (TRLFS). J. Alloys Compd. 1998, 271-273, 765-768. [CrossRef]

17. Gabriel, U.; Charlet, L.; Schläpfer, C.W.; Vial, J.C.; Brachmann, A.; Geipel, G. Uranyl surface speciation on silica particles studied by time-resolved laser-induced fluorescence spectroscopy. J. Colloid Interface Sci. 2001, 239, 358-368. [CrossRef]

18. Chisholm-Brause, C.J.; Berg, J.M.; Little, K.M.; Matzner, R.A.; Morris, D.E. Uranyl sorption by smectites: Spectroscopic assessment of thermodynamic modelling. J. Colloid Interface Sci. 2004, 277, 366-382. [CrossRef]

19. Wang, Z.; Zachara, J.M.; Gassman, P.L.; Liu, C.; Qafoku, O.; Yantasee, W.; Catalano, J.G. Fluorescence spectroscopy of U(VI)silicates and U(VI)-contaminated Hanford sediment. Geochim. Cosmochim. Acta 2005, 69, 1391-1403. [CrossRef]

20. Trepte, P. Sorption von Radionukliden an Tongestein: Spektroskopische Referenzdaten. Diploma Thesis, University of Applied Science, Dresden, Germany, 2006.

21. Trepte, P.; Brendler, V. Supporting Information (c) TRLFS properties of uranium(VI) sorbed onto silica gel in Krepelova, A.; Brendler, V.; Sachs, S.; Baumann, N.; Bernhard, G. Environ. Sci. Technol. 2007, 41, 6142-6147.

22. Ilton, E.S.; Wang, A.; Boily, J.-F.; Qafoku, O.; Rosso, K.M.; Smith, S.C. The effect of $\mathrm{pH}$ and time on the extractability and speciation of uranium(VI) sorbed to $\mathrm{SiO}_{2}$. Environ. Sci. Technol. 2012, 46, 6604-6611. [CrossRef]

23. Othmane, G.; Allard, T.; Vercouter, T.; Morin, G.; Fayek, M.; Calas, G. Luminescence of uranium-bearing opals: Origin and use as a pH record. Chem. Geol. 2016, 423, 1-6. [CrossRef]

24. Saleh, A.S.; Lee, J.-Y.; Jo, Y.; Yun, J.-I. Uranium(VI) sorption complexes on silica in the presence of calcium and carbonate J. Environ. Radioact. 2018, 182, 63-69. [CrossRef]

25. Chisholm-Brause, C.J.; Berg, J.M.; Matzner, R.A.; Morris, D.E. Uranium(VI) sorption complexes on montmorillonite as a function of solution chemistry. J. Colloid Interface Sci. 2001, 233, 38-49. [CrossRef]

26. Froideval, A.; Nero, M.D.; Barillon, R.; Hommet, J.; Mignot, G. pH dependence of uranyl retention in a quartz/solution system: An XPS study. J. Colloid Interface Sci. 2003, 266, 221-235. [CrossRef]

27. Froideval, A.; Nero, M.D.; Gaillard, C.; Barillon, R.; Rossini, I.; Hazemann, J.L. Uranyl sorption species at low coverage on Al-hydroxide: TRLFS and EXAFS studies. Geochim. Cosmochim. Acta 2006, 70, 5270-5284. [CrossRef]

28. Denning, R.G. Electronic structure and bonding in actinyl ions and their analogs. J. Phys. Chem. A 2007, 111, 4125-4143. [CrossRef]

29. Redmond, M.P.; Cornet, S.M.; Woodall, S.D.; Whittaker, D.; Collison, D.; Helliwell, M.; Natrajan, L.S. Probing the local coordination environment and nuclearity of uranyl(VI) complexes in non-aqueous media by emission spectroscopy. Dalton Trans. 2011, 40, 3914-3926. [CrossRef]

30. Drobot, B.; Steudtner, R.; Raff, J.; Geipel, G.; Brendler, V.; Tsushima, S. Combining luminescence spectroscopy, parallel factor analysis and quantum chemistry to reveal metal speciation-A case study of uranyl(VI) hydrolysis. Chem. Sci. 2015, 6, 964-972. [CrossRef]

31. Jung, E.C.; Kim, T.-H.; Kim, H.-K.; Cho, H.-R.; Cha, W. Excitation and emission properties of adsorbed U(VI) on amorphous silica surface. J. Nucl. Fuel Cycle Waste Technol. 2020, 18, 497-508. [CrossRef]

32. Moulin, C.; Laszak, I.; Moulin, V.; Tondre, C. Time-resolved laser-induced fluorescence as a unique tool for low-level uranium speciation. Appl. Spectrosc. 1998, 52, 528-535. [CrossRef]

33. Wang, G.; Su, Y.; Monts, D.L. Parametric investigation of laser-induced fluorescence of solid-state uranyl compounds. J. Phys. Chem. A 2008, 112, 10502-10508. [CrossRef]

34. Eliet, V.; Bidoglio, G. Kinetics of the laser-induced photoreduction of U(VI) in aqueous suspensions of $\mathrm{TiO}_{2}$ particles. Environ. Sci. Technol. 1998, 32, 3155-3161. [CrossRef]

35. Selli, E.; Eliet, V.; Spini, M.R.; Bidoglio, G. Effects of humic acids on the photoinduced reduction of U(VI) in the presence of semiconducting $\mathrm{TiO}_{2}$ particles. Environ. Sci. Technol. 2000, 34, 3742-3748. [CrossRef]

36. Landmann, M.; Rauls, E.; Schmidt, W.G. The electronic structure and optical response of rutile, anatase and brookite TiO 2 . J. Phys. Condens. Matter 2012, 24, 195503. [CrossRef]

37. DiStefano, T.H.; Eastman, D.E. The band edge of amorphous $\mathrm{SiO}_{2}$ by photoinjection and photoconductivity measurements. Solid State Commun. 1971, 9, 2259-2261. [CrossRef]

38. Saito, T.; Sao, H.; Ishida, K.; Aoyagi, N.; Kimura, T.; Nagasaki, S.; Tanaka, S. Application of parallel factor analysis for timeresolved laser fluorescence spectroscopy: Implication for metal speciation study. Environ. Sci. Technol. 2010, 44, 5055-5060. [CrossRef]

39. Saito, T.; Aoyagi, N.; Kimura, T. Time-resolved laser-induced fluorescence spectroscopy combined with parallel factor analysis: A robust speciation technique for $\mathrm{UO}_{2}^{2+}$. J. Radioanal. Nucl. Chem. 2015, 303, 1129-1132. [CrossRef]

40. Drobot, B.; Bauer, A.; Steudtner, R.; Tsushima, S.; Bok, F.; Patzschke, M.; Raff, J.; Brendler, V. Speciation studies of metals in trace concentrations: The mononuclear uranyl(VI) hydroxo complexes. Anal. Chem. 2016, 88, 3548-3555. [CrossRef] 
41. Wang, Z.; Zachara, J.M.; Mckinley, J.P.; Smith, S.C. Cryogenic laser induced U(VI) fluorescence studies of a U(VI) substituted natural calcite: Implications to U(VI) speciation in contaminated Hanford sediments. Environ. Sci. Technol. 2005, 39, 2651-2659. [CrossRef]

42. Chang, H.-S.; Korshin, G.V.; Wang, Z.; Zachara, J.M. Adsorption of uranyl on gibbsite: A time-resolved laser-induced fluorescence spectroscopy study. Environ. Sci. Technol. 2006, 40, 1244-1249. [CrossRef]

43. Boily, J.-F.; Rosso, K.M. Crystallographic controls on uranyl binding at the quartz/water interface. Phys. Chem. Chem. Phys. 2011, 13, 7845-7851. [CrossRef]

44. Stanton, J.; Maatman, R.W. The reaction between aqueous uranyl ion and the surface of silica gel. J. Colloid Sci. 1963, 18, 132-146. [CrossRef]

45. Levine, L.P.; Ready, J.F.; Bernal, G.E. Gas deposition produced by a giant pulse laser. J. Appl. Phys. 1967, 38, 331-336. [CrossRef]

46. Hall, R.B. Pulsed-laser-induced deposition studies of the kinetics of surface reactions. J. Phys. Chem. 1987, 91, 1007-1015. [CrossRef]

47. George, S.M. Laser-induced thermal desorption. In Physical Methods of Chemistry Series, 2nd ed.; Rossiter, B.W., Baetzold, R.C., Eds.; John Wiley \& Sons, Inc.: Hoboken, NJ, USA, 1993; Volume IXA, p. 453.

48. Voumard, P.; Zenobi, R. Laser-induced thermal desorption of aniline from silica surfaces. J. Chem. Phys. 1995, 103, 6795-6805. [CrossRef]

49. Amadelli, R.; Maldotti, A.; Sostero, S.; Carassiti, V. Photodeposition of uranium oxides onto $\mathrm{TiO}_{2}$ from aqueous uranyl solutions. J. Chem. Soc. Faraday Trans. 1991, 87, 3267-3273. [CrossRef] 